دراسة اقتصادية لأثز استخدام الصوب الزراعية على كفاعة استخدام بعض الموارد

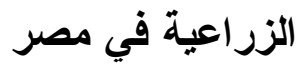

مها عبد الفتاح إبراهيم سيد ومنار عزت محمد بيومي

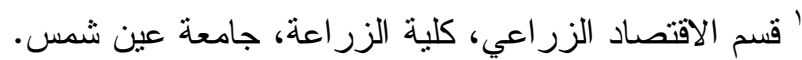

CrossMark

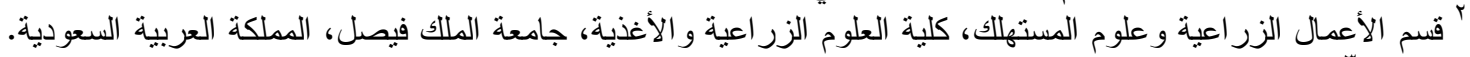

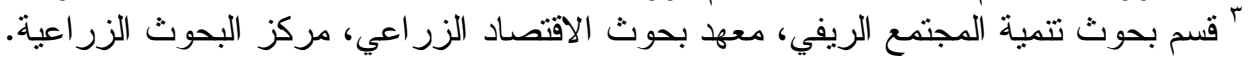

Received on: 30/1/2019

Accepted for publication on: 18/2/2019

مقدمة:

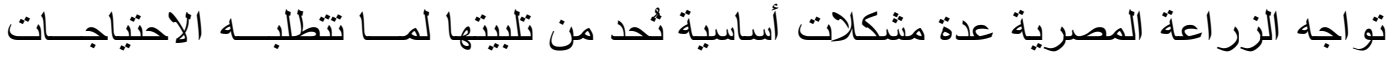

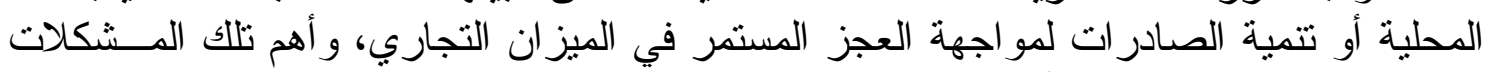

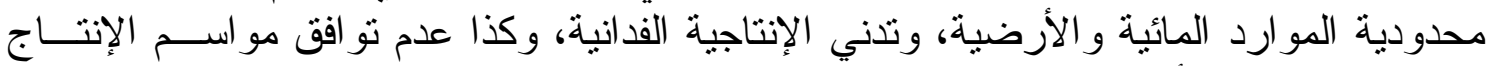

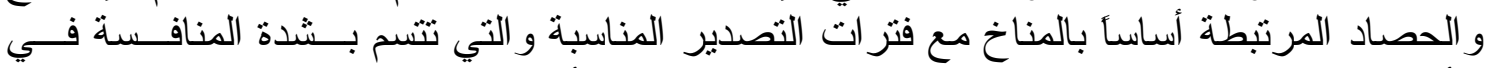

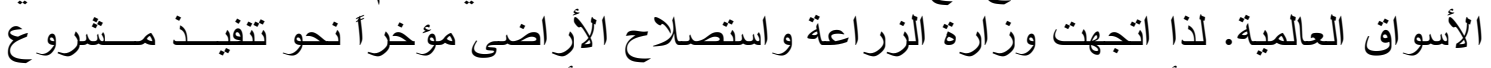

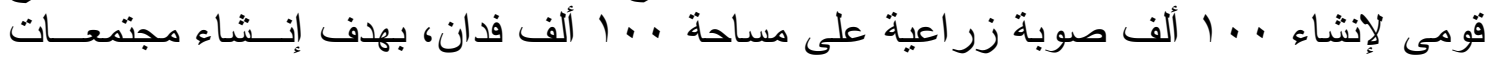

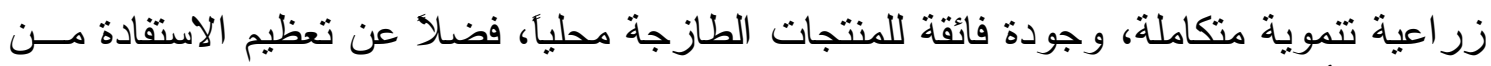

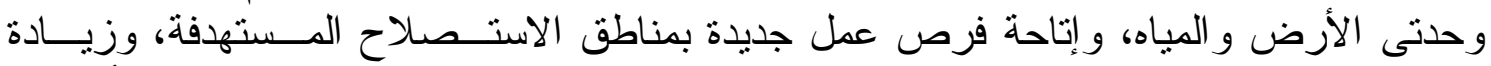

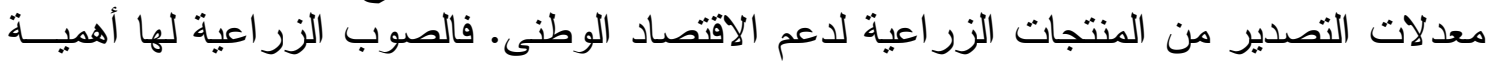

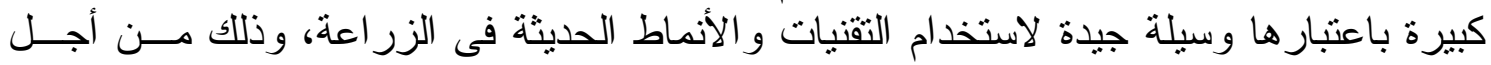

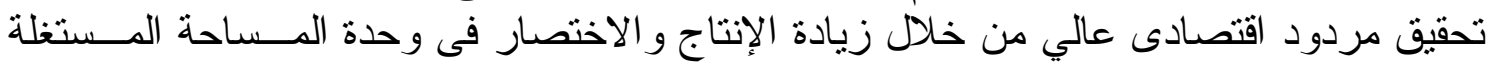

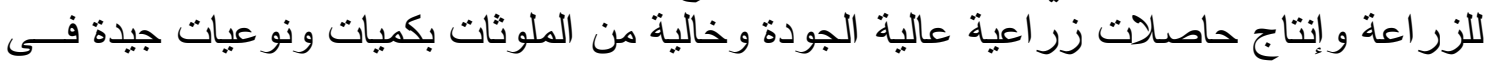

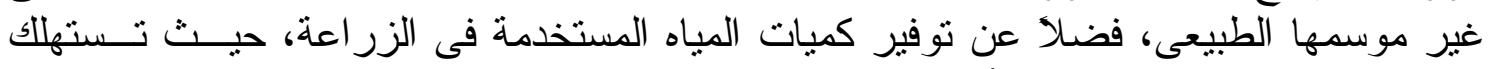

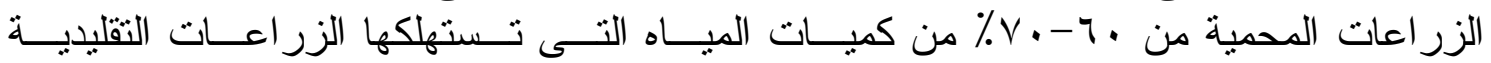

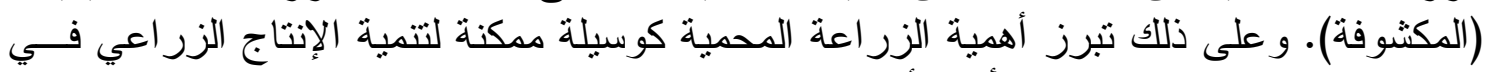

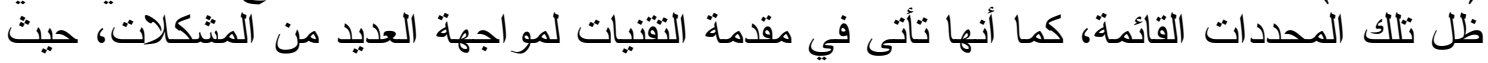

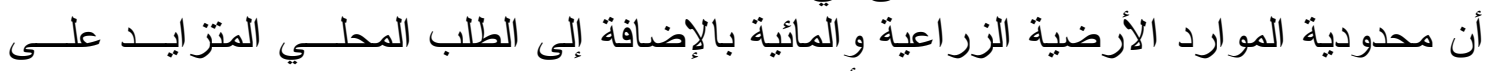

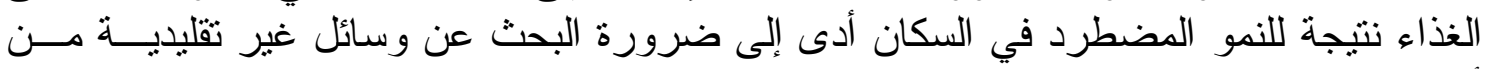

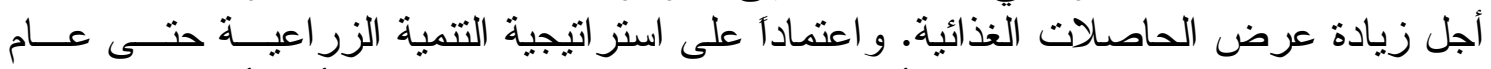

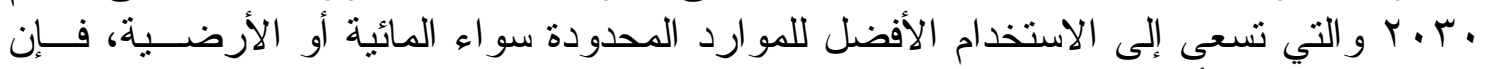

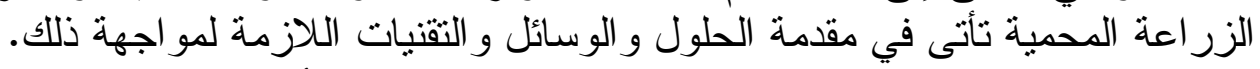

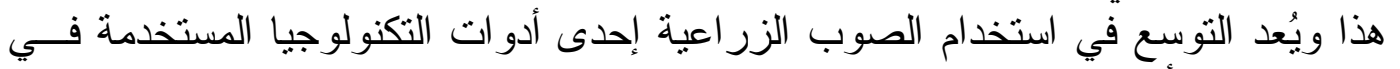

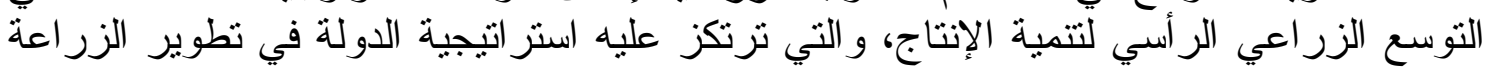

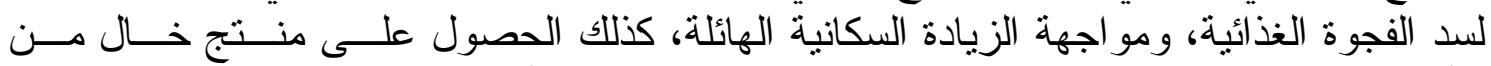

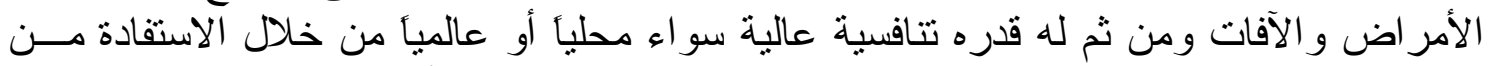

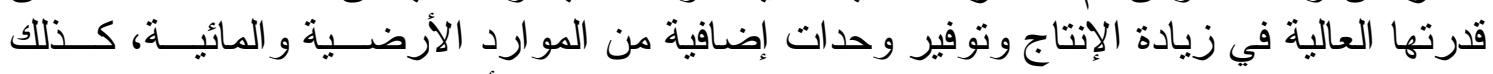

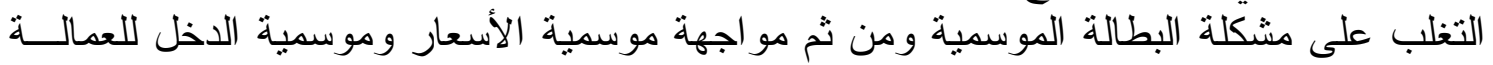

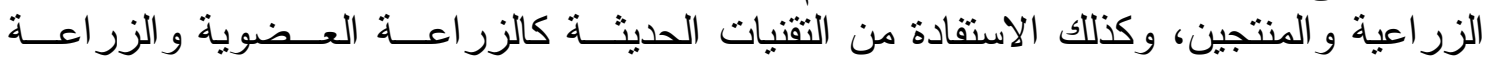

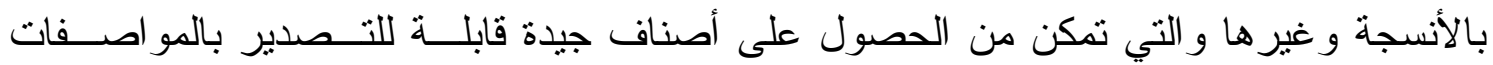

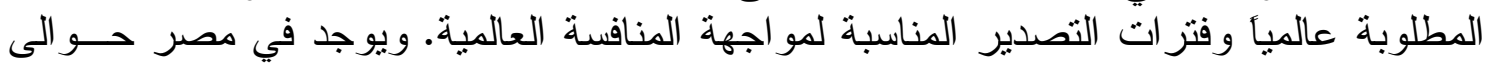
1 1 ـ . .

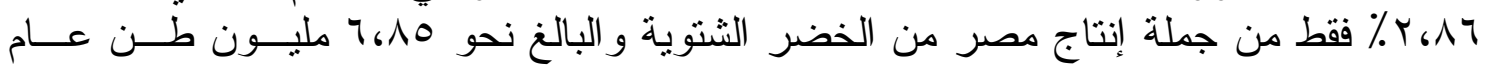

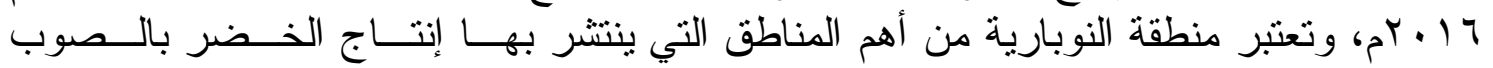




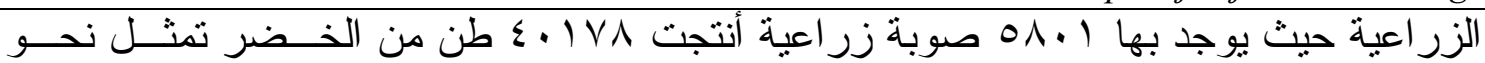

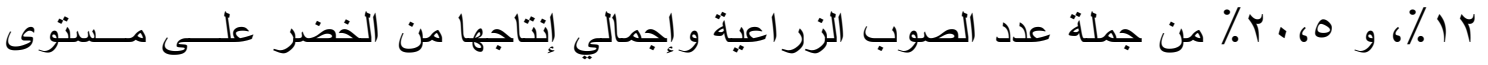

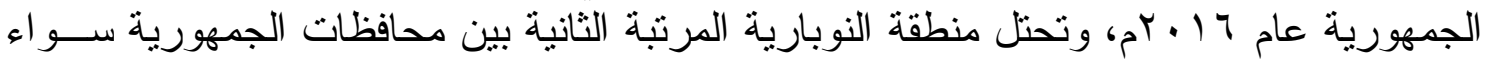

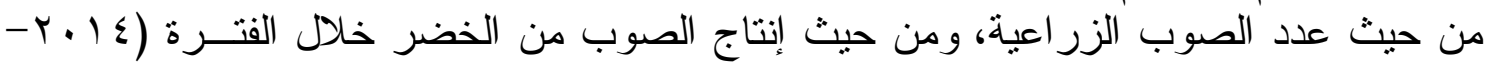

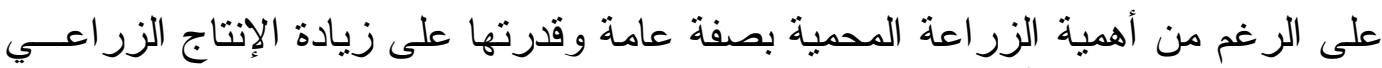

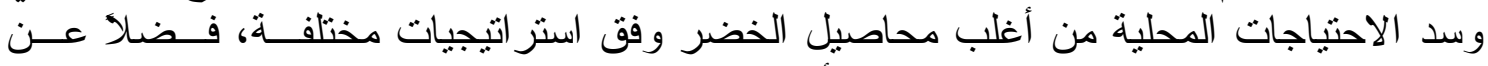

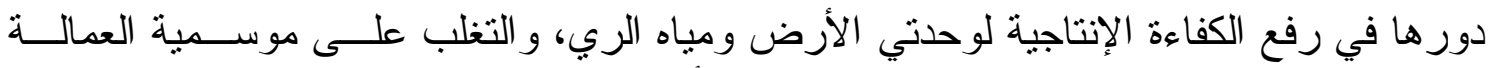

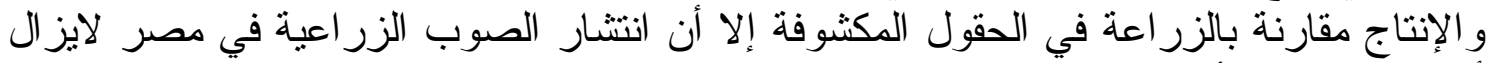

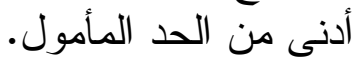

يستهدف البحث بصفة عامة التعرف على دور الصوب الزر اعية في رفع كفاء اســتخدام

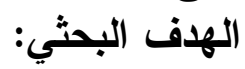

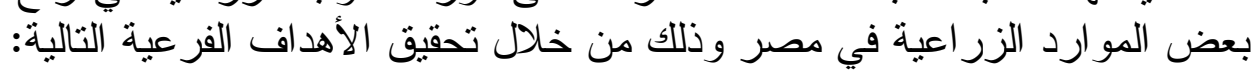

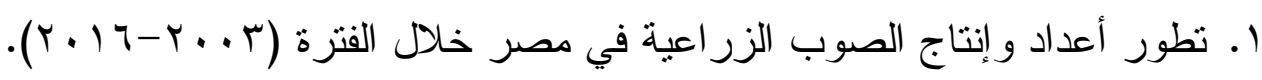
r. تقدير موسمية العمالة الزر اعية و إمكانية الاستفادة منها في الزر اعة بالصوب الزوب الزر اعية.

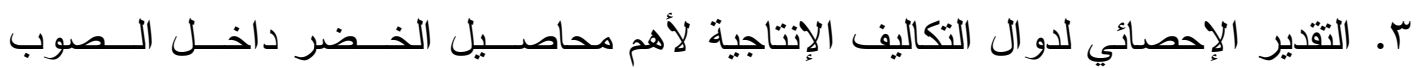
الزر اعية بعينة الدر اسة بمنطقة النوبارية.

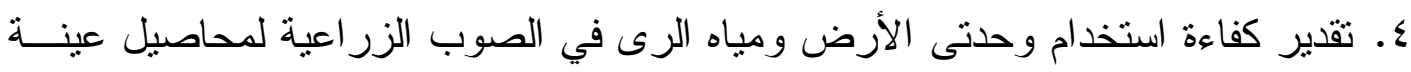

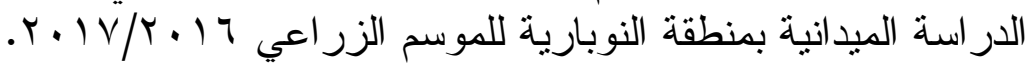

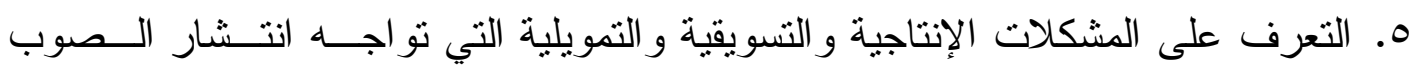
الزر اعية بعينة الدر اسة المبدانية.

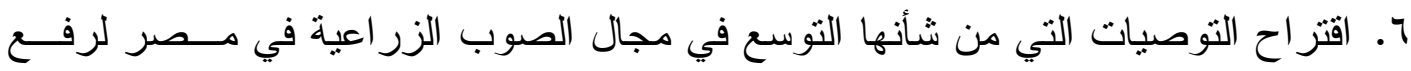

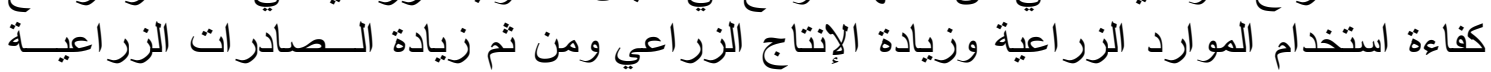
المصرية. الطريقة البحثية ومصادر البيانات:

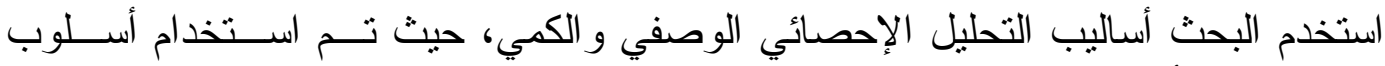

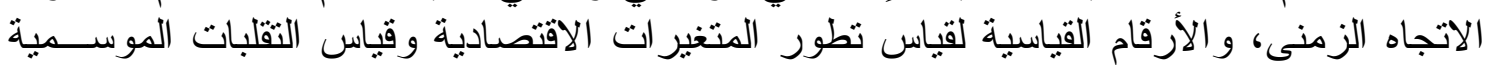

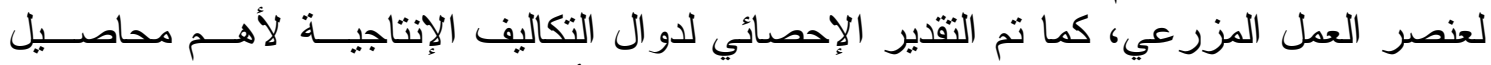

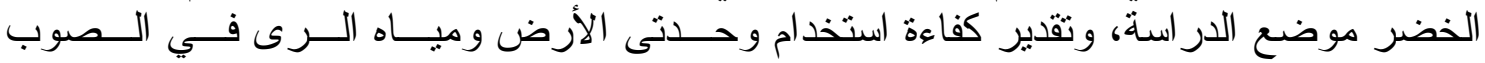

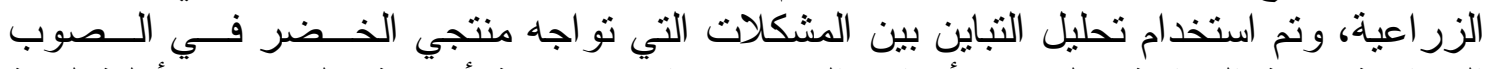
الزر اعية بعينة الدراسة. ولتحقيق أهداف البحث فقد اعتمد بصفة أسأسية على بيانات أولية لعينة لعينة

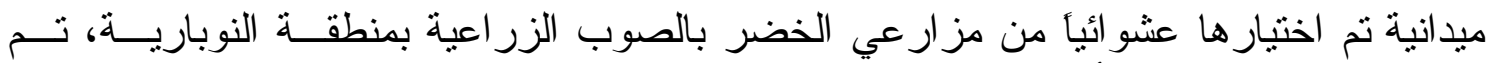

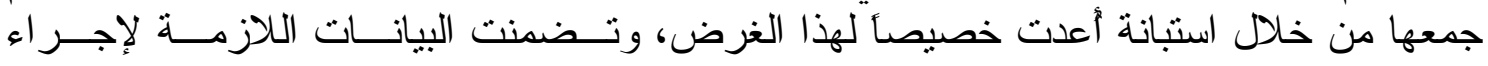

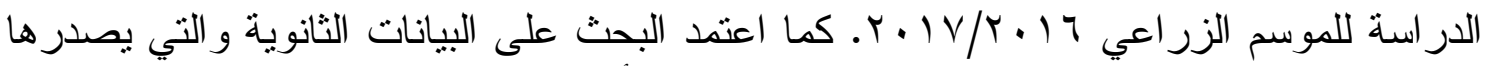

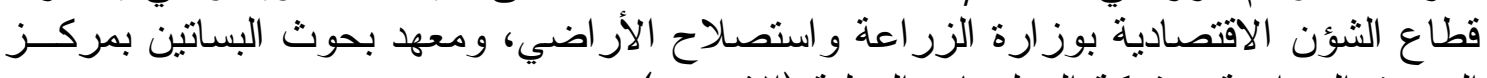

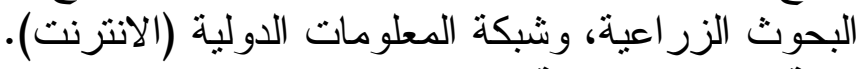




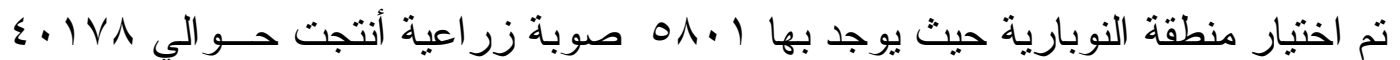

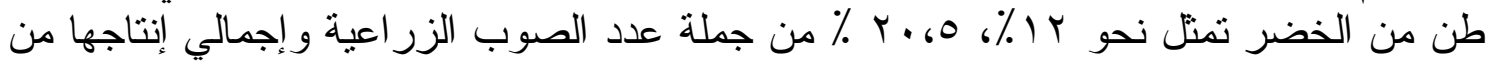

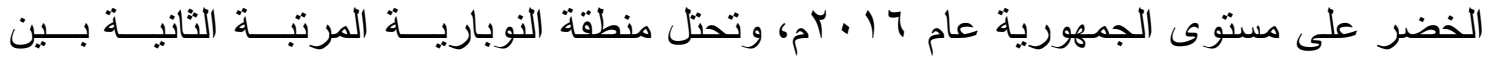

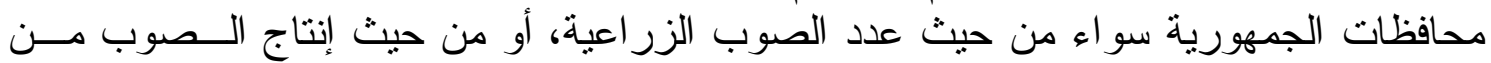

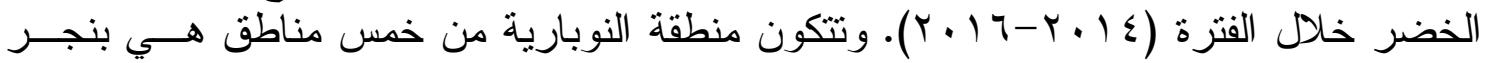

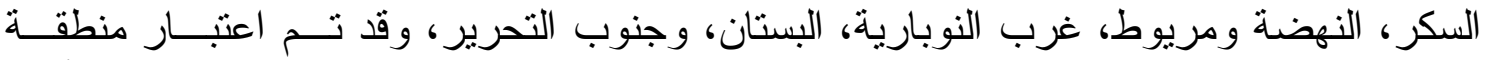

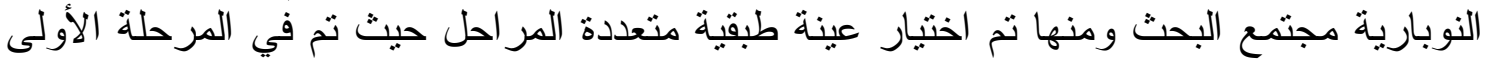

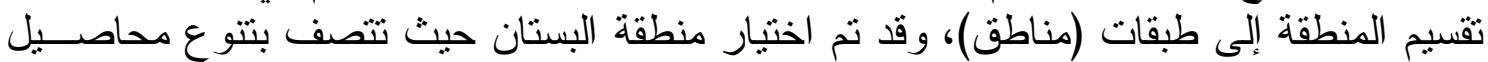

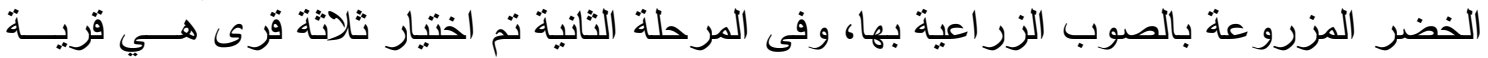

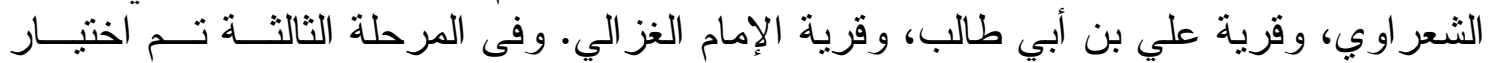

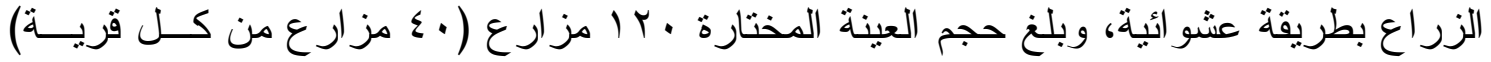

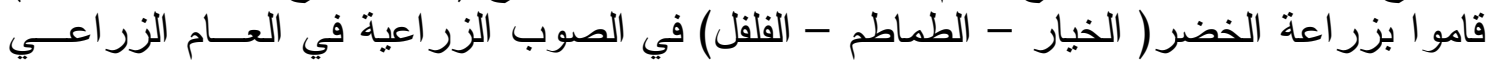

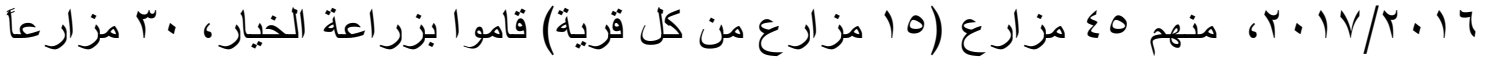

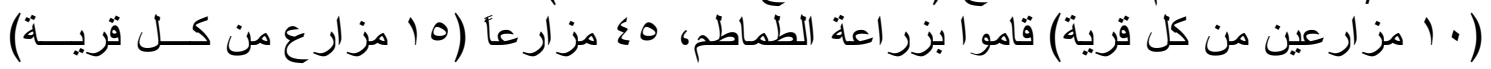
قامو ا بزر اعة الفلفل.

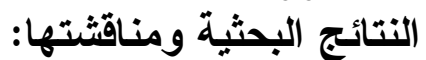

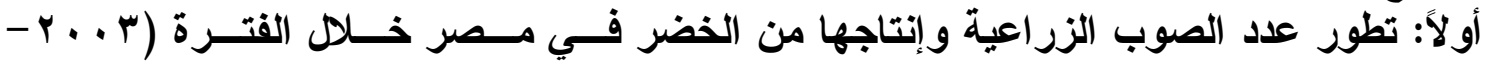

\section{ا ـ تطور عدد الصوب الزراعية:}

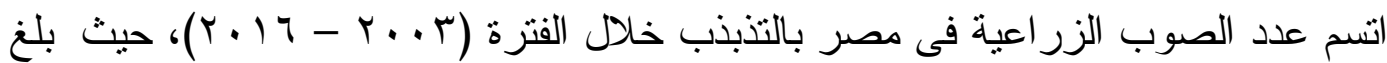

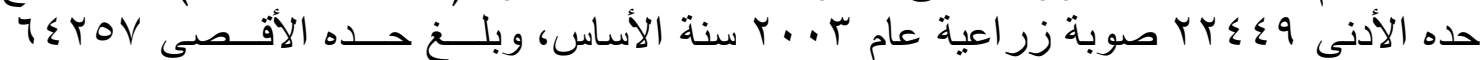

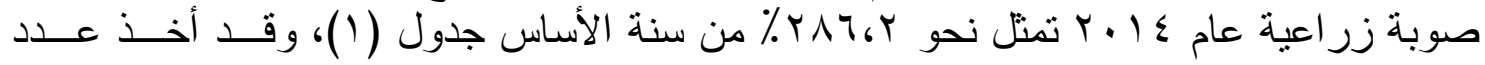

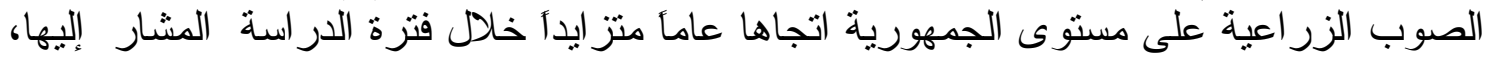

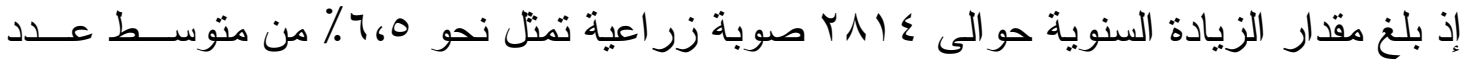

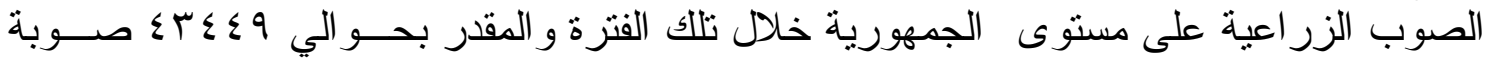

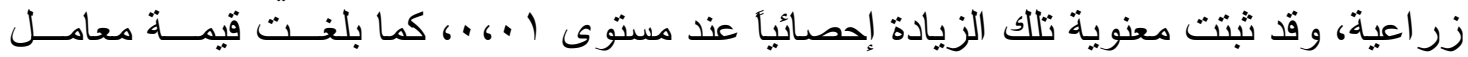

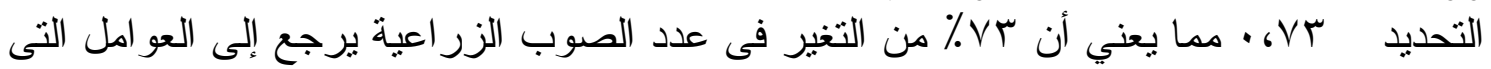

يعكسها متغير الزمن، جدول (r).

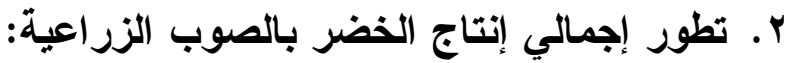

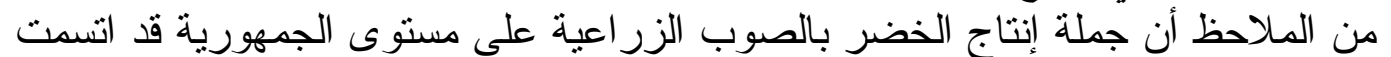

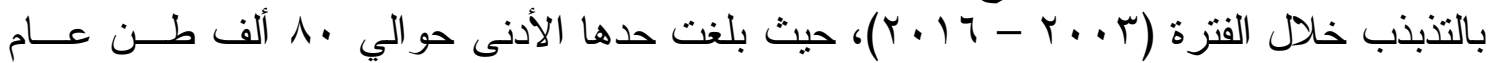

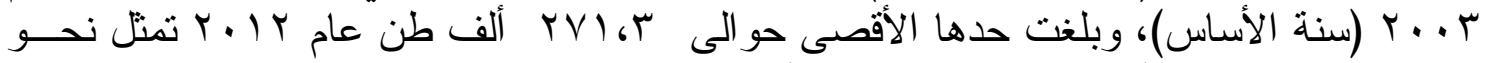

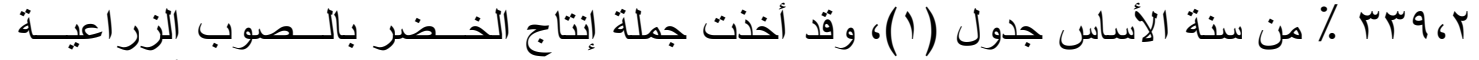

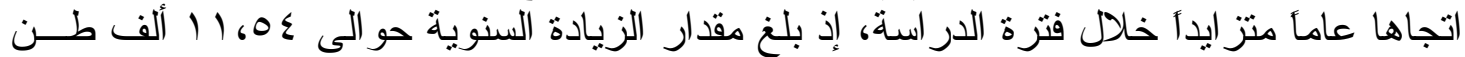

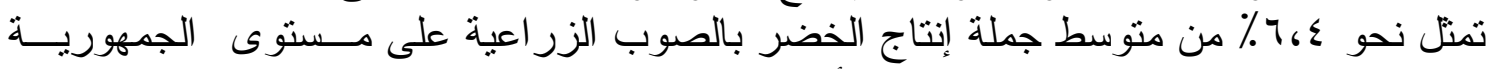

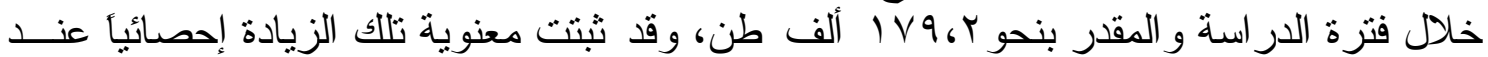

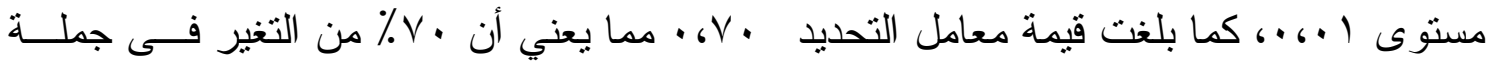

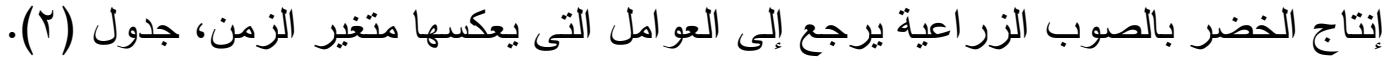




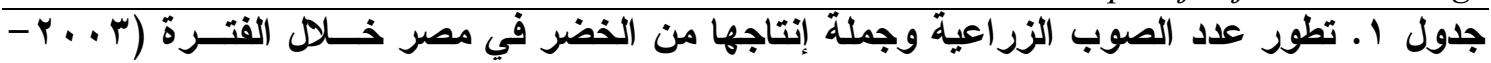

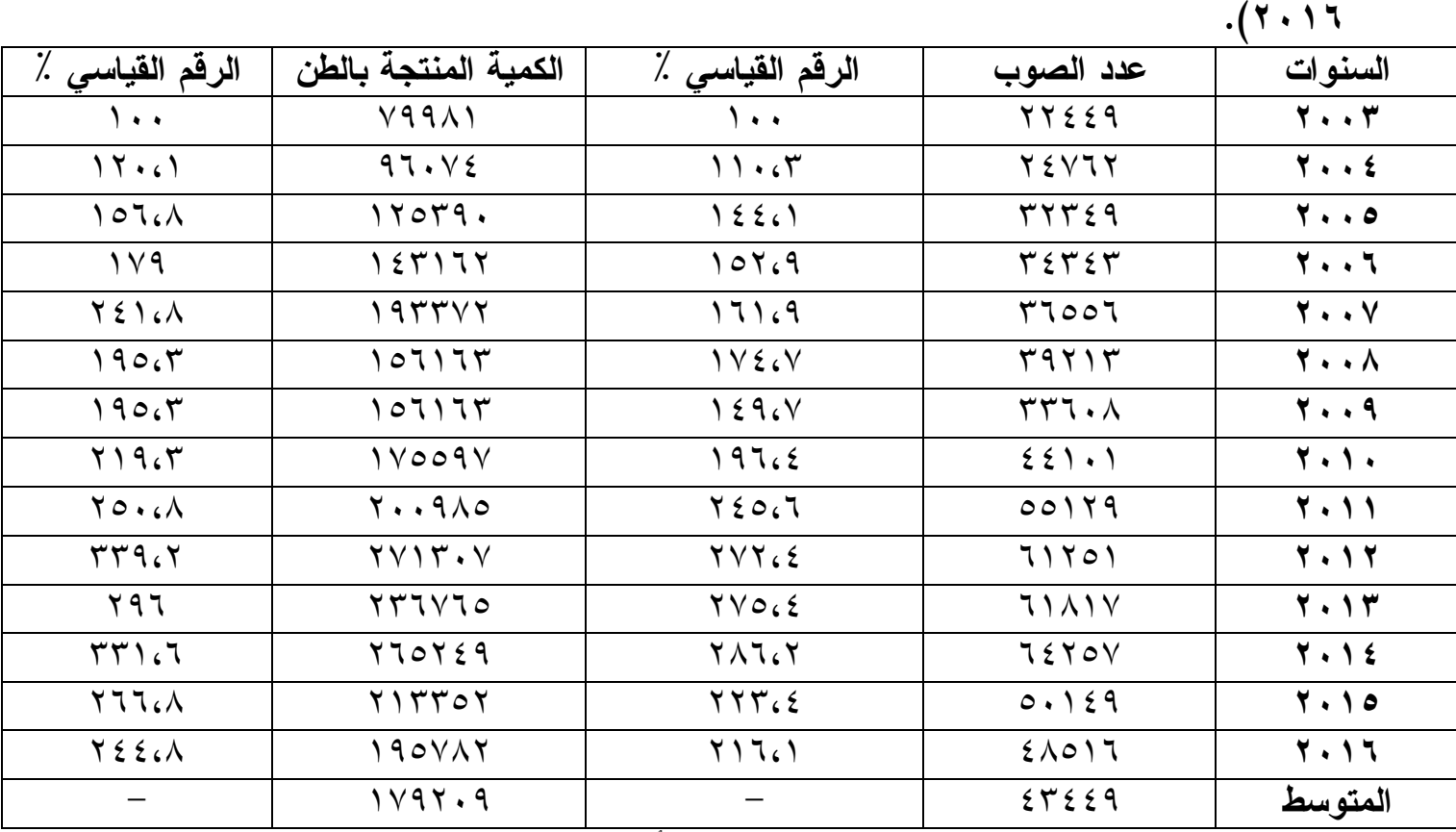

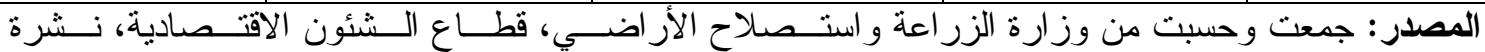
الإحصاءات الزر اعية، أعداد متفرقة.

جدول r . نتائج التقدير الاحصائي لمعادلات الاتجاه الزمني لعدد الصوب الزراعية وجملة إنتاجها مسن

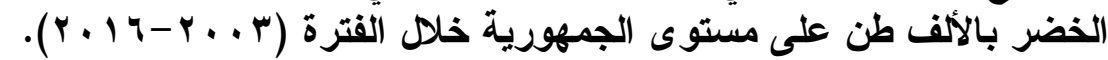

\begin{tabular}{|c|c|c|c|c|c|c|c|c|}
\hline لية & $\mathbf{T}_{\mathbf{B}}$ & $\mathbf{F}$ & $\mathbf{R}^{2}$ & $\begin{array}{c}\text { التغنير } \\
\text { السنوى \% }\end{array}$ & الحسابى & $\boldsymbol{\beta}$ & $\boldsymbol{\alpha}$ & البيان \\
\hline ** & $0, V$ & rT & . & 7.0 & $\varepsilon r \leqslant \leqslant 9$ & YMI & rTrET, & عدد الصوب (صوبة) \\
\hline$* *$ & $0, r$ & $r V_{6} q$ & . rV & $T ، \varepsilon$ & IV9.r & $11,0 \varepsilon$ & 94.7 & جملة الإتتاج ( ألف طن) \\
\hline
\end{tabular}

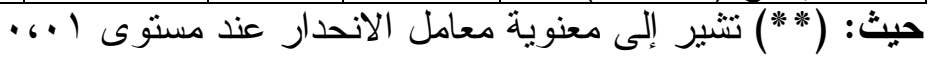

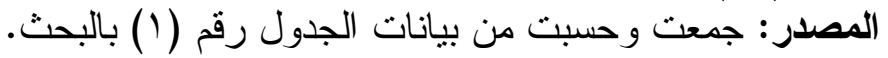

ثانياً: الأهمية النسبية للصوب الزراعية وإجمالي إنتاجها من الخضر في مــصر خــله

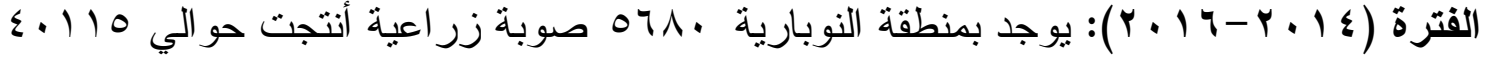

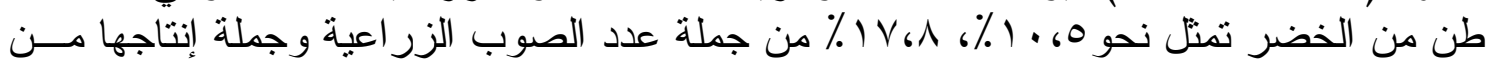

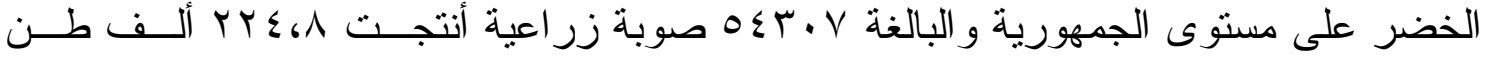

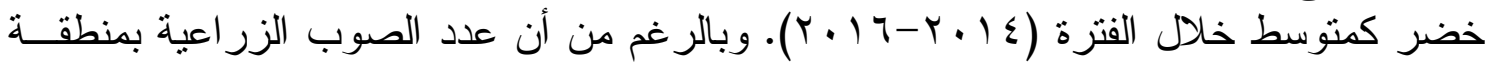
النوبارية يمثل نحو 0، • 1 من إجمالي عدد الصوب على مستوى الجمهورية إلا أن إنتاجها من اعنه

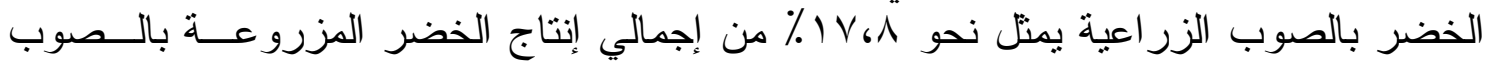
الزر اعية على مستوى الجمهورية، الأمر الذي يشير إلى زيادة الانتاجية بها مقارنة بباقي أنحــاء التهاء

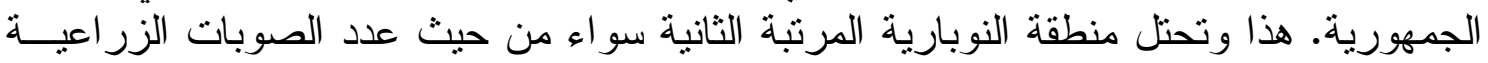

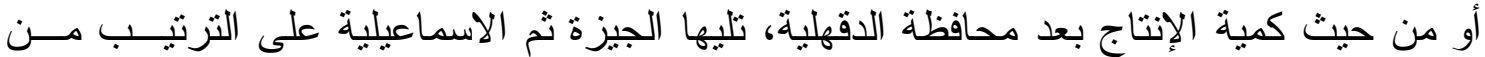

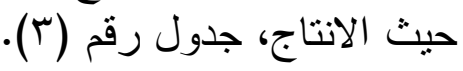


Website: www.aun.edu.eg/faculty_agriculture/journals_issues_form.php E-mail: ajas@aun.edu.eg

جدول ب. التوزيع الجغرافي للصوب الزراعية و إنتاجها من الخضر على مستوى محافظات الجمهورية

\begin{tabular}{|c|c|c|c|c|c|c|}
\hline \multicolumn{3}{|c|}{ الإنتاج (بالطن) } & \multicolumn{3}{|c|}{ عدد الصوب (بالصوبة) } & \multirow[b]{2}{*}{ المحافظات } \\
\hline الترتيب & الأهمية & الكمية - ال & الترتيب & الاهمية النسبية & 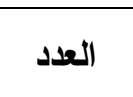 & \\
\hline $1 \varepsilon$ & $.6 \mathrm{~V}$ & $17 \wedge 7$ & IT & 1,6 & $9 M \mathrm{~V}$ & الأسكندرية \\
\hline 0 & $V_{6} 0$ & 1710. & 1. & 1,11 & $9 \wedge r$ & البحـيزة \\
\hline 7 & 0 & $111 \leq 0$ & $\varepsilon$ & $\left.\Lambda_{6}\right)$ & 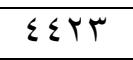 & الغزبيـــة \\
\hline 1. & 1,2 & rıA & $1 \varepsilon$ & 1.7 & 107 & كفر الشيخ \\
\hline 1 & rV.O & $\Lambda \Sigma \Gamma \leqslant \Lambda$ & 1 & $\varepsilon r_{6} T$ & $r T \leq T)$ & الدقهليــة \\
\hline$\Lambda$ & $1 . \mathrm{V}$ & rAVV & 7 & $\varepsilon$ & $r \backslash \wedge \Lambda$ & دمبــــــاط \\
\hline V & $\varepsilon_{6 \wedge} \wedge$ & 1.790 & $\mathrm{~V}$ & r. & $|V| \varepsilon$ & الشــرقية \\
\hline$\varepsilon$ & $\left.\Lambda_{6}\right)$ & 11174 & 0 & $V_{6} \Lambda$ & EYYT & الإسماعيلية \\
\hline 11 & 1,4 & TVTE & $\Lambda$ & $r_{6} 7$ & $1 \leqslant 19$ & الســـويس \\
\hline 9 & 1.0 & $r$ r^q & 9 & Y.O & ITVY & المنوفيــة \\
\hline$r$ & 1.67 & TrNTE & $r$ & 967 & OYYI & الجيــزة \\
\hline $1 \pi$ & 1 & TrOV & 11 & 1,1 & $90 \mathrm{r}$ & الو ادي الجديد \\
\hline$r$ & $1 V_{6} A$ & 5.110 & $r$ & 1.60 & 071. & النوبارية \\
\hline IY & 1,1 & rONK & 14 & 1.7 & $\Lambda \vee r$ & باقي المحافظات \\
\hline- & $1 \cdots$ & TY $\leqslant \vee q \varepsilon$ & - & $1 \cdots$ & $0 \leqslant r \cdot V$ & جملة الجمهورية \\
\hline
\end{tabular}
الإحصاءات الزر اعية، أعداد متفرقة.

ثالثاً: موسمية العمالة الزراعيـــة و إمكاتية الاستفادة منها في الزر اعة بالصوب الزراعية:

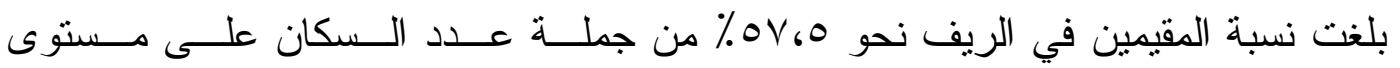

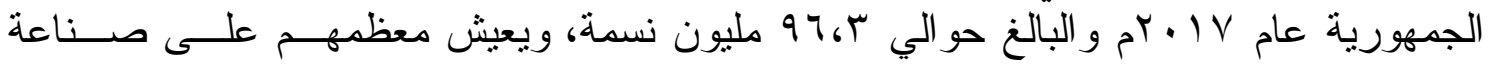

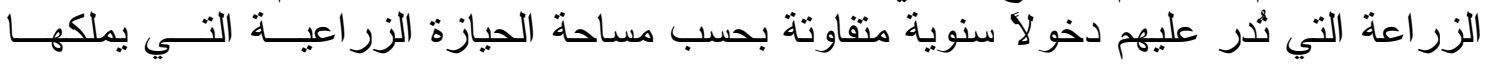

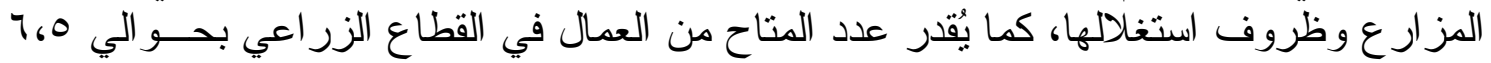

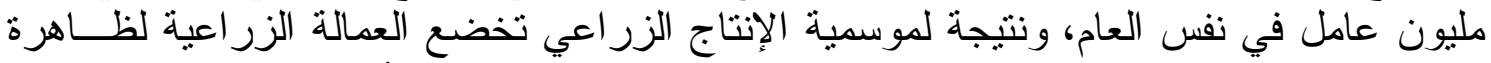

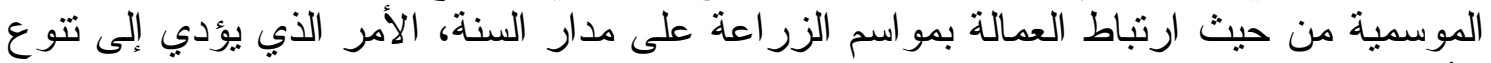

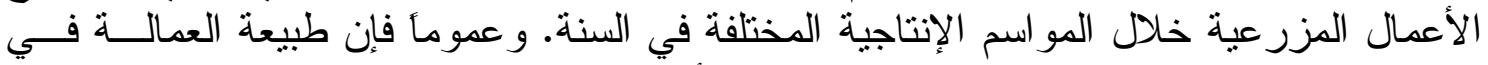

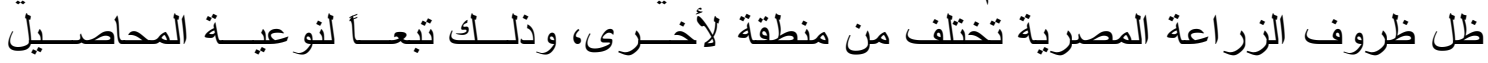

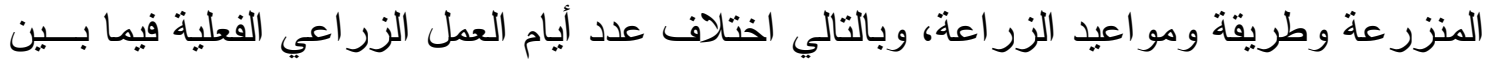

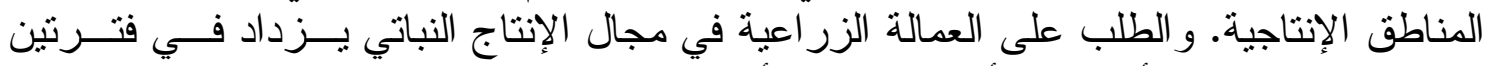

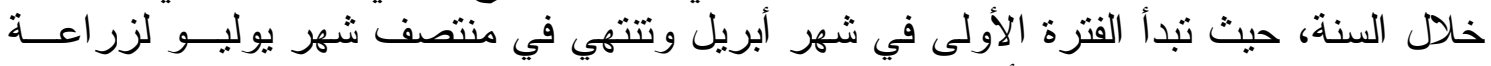

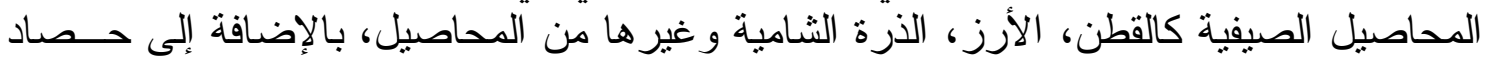

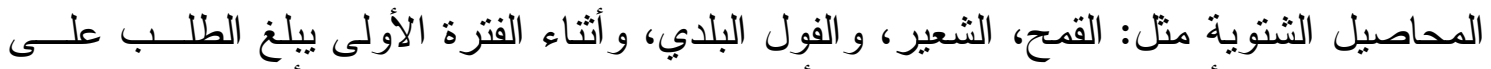

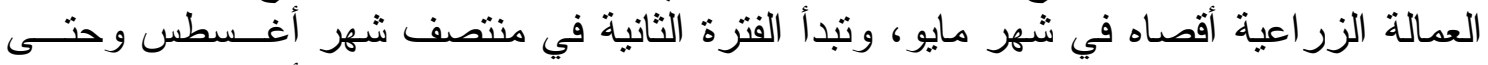

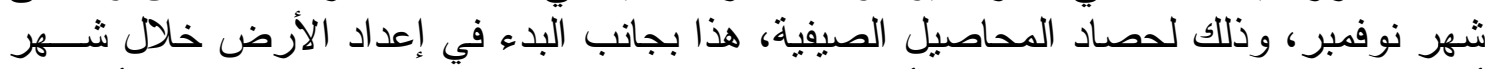

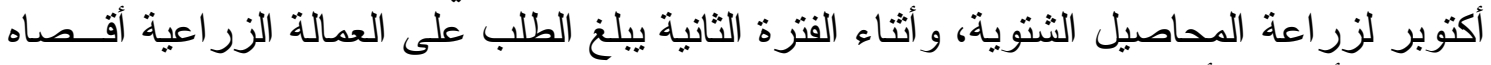

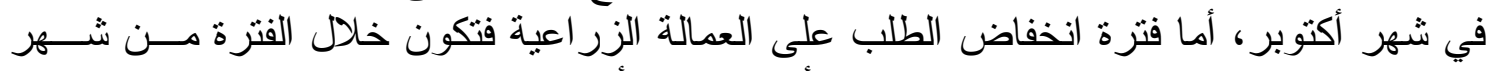

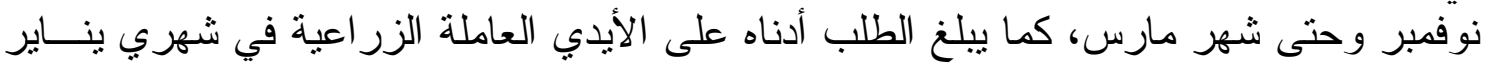



http://ajas.journals.ekb.eg/

وفبر اير • وتعتبر دارسة التغير ات الموسمية للعمالة الزر اعية من الأهمية بمكان بالنسبة للمنتجين

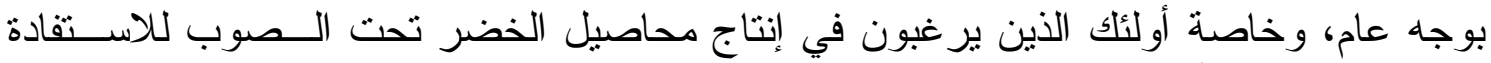

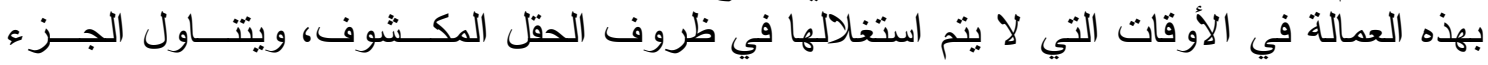

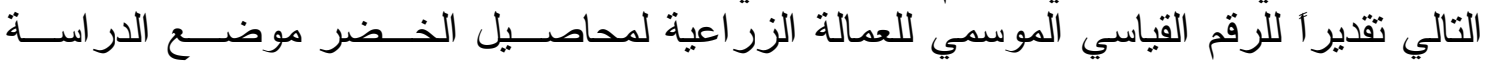

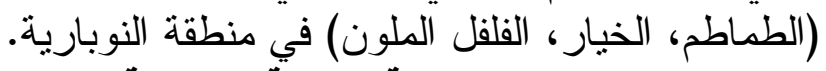

ا ـ التقلبات الموسمية للعمالة الشهرية لمحصول الطماطم في ظروف الحقل المكشوف:

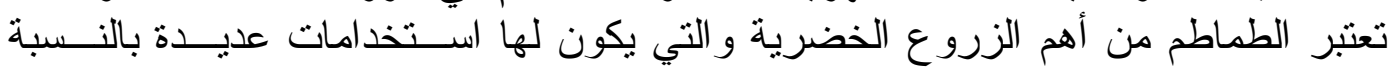

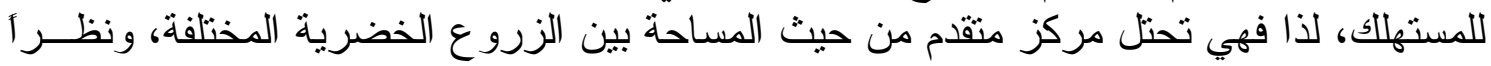

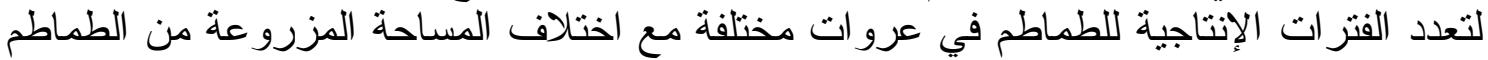

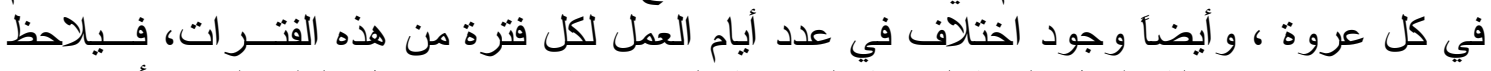

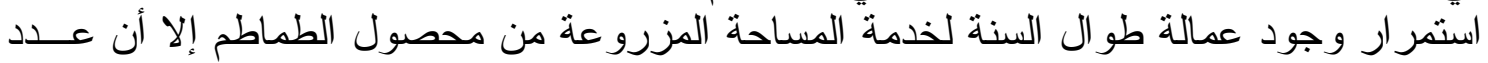

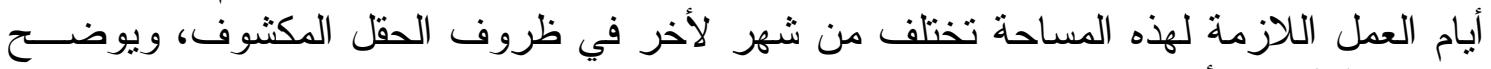

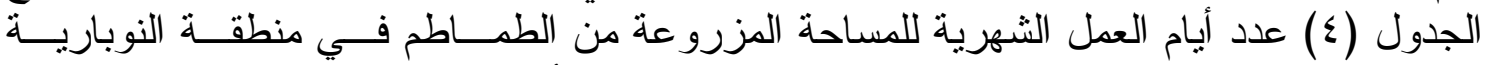

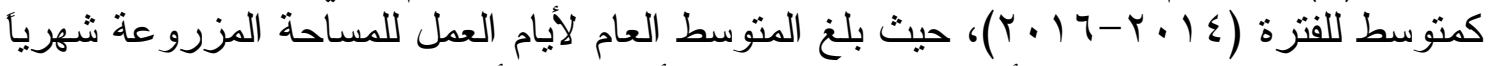

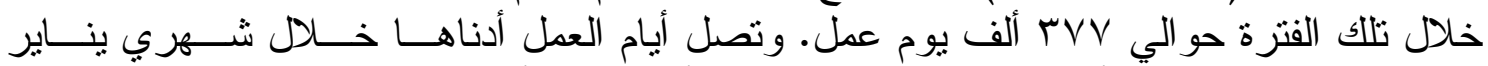

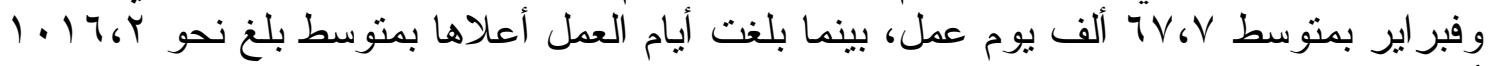
ألف يوم عمل خلائل شهري مارس و إيريل.

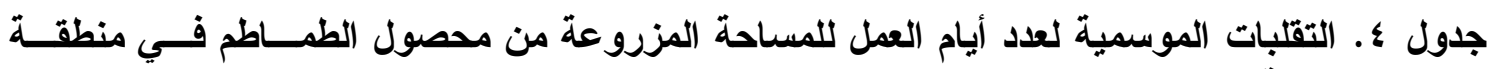

\begin{tabular}{|c|c|c|c|c|}
\hline الموسمي للعمالة: القياسي & إجمالي أيام العمل للمساحة & للطماطم النيام العمل & للطماطم الشتّوي العمل & الشهور \\
\hline 11 & $T V \vee \varepsilon \varepsilon$ & 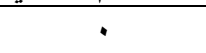 & $T \vee V \leq \varepsilon$ & 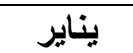 \\
\hline 11 & $T V V \leqslant \varepsilon$ & - & $T V V \varepsilon \varepsilon$ & فبر اير \\
\hline r7960 & 1.1717. & . & 1.1717. & مارس - - مارس \\
\hline 17960 & 1.1717. & $\cdot$ & 1.1717. & إبريل \\
\hline$T V$ & 1.1717 & - & 1.1717 & مايو \\
\hline$\varepsilon \cdot 6 \wedge$ & $10 r 9 \leq 0$ & $10 r 9 \leq 0$ & $\cdot$ & يونيه \\
\hline 91 & r79ะ71 & एч9ะ71 & . & يوليو \\
\hline $9 Y_{6} 7$ & $r \leq \wedge 9 \leq r$ & $r \leq \wedge 9 \leq r$ & . & أغسطس \\
\hline 1.1 .9 & $\sum 1.0 Y$. & $\sum 1.0 Y$. & . & سبتمبر \\
\hline$\wedge \vee, 1$ & 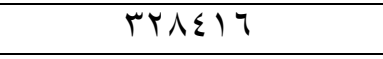 & rYAミIT & · & أكتوبر \\
\hline $1 \Gamma \varepsilon_{6} \Lambda$ & $0.1 \cdot 1$. & $\cdot$ & $0.1 \cdot 1$. & نوفمبر \\
\hline 10.9 & 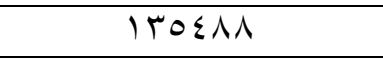 & - & $1 r 0 \leqslant \wedge \Lambda$ & ديسمبر \\
\hline $1 \cdots$ & TVV.YTG & - & - & المتوسط \\
\hline
\end{tabular}

المصدر: جمعت وحسبت من بيانات:

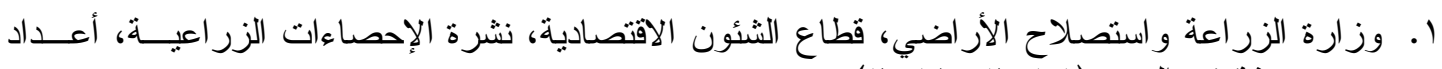

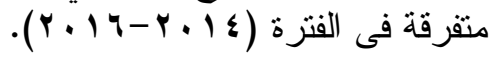

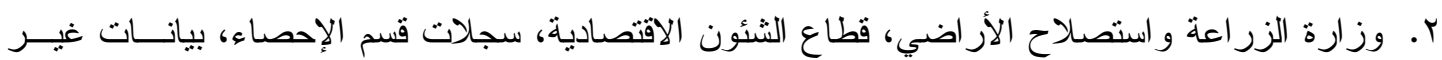

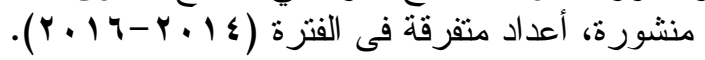

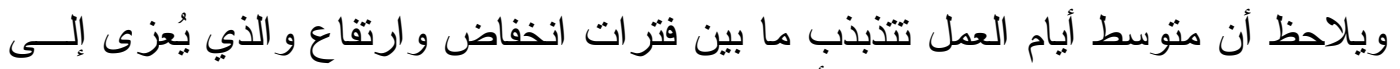

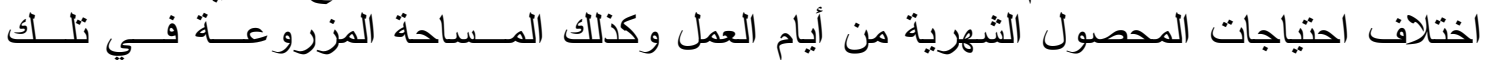




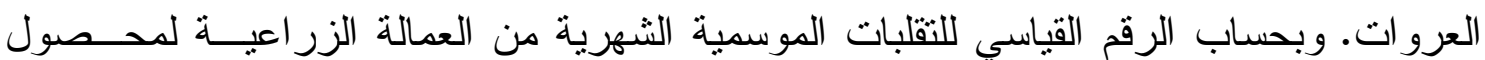

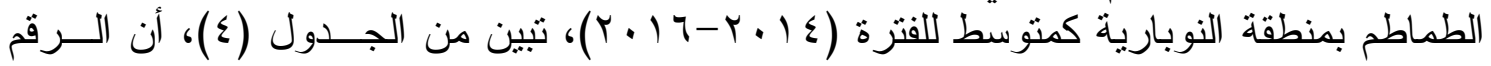

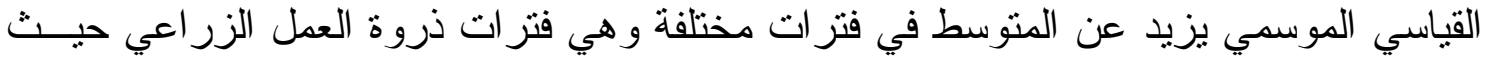

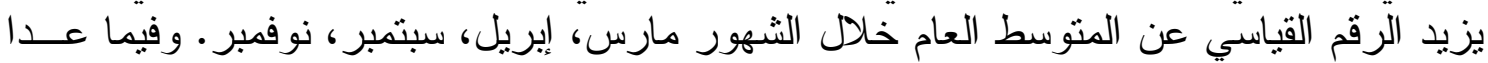

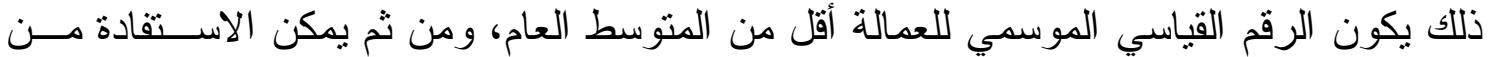

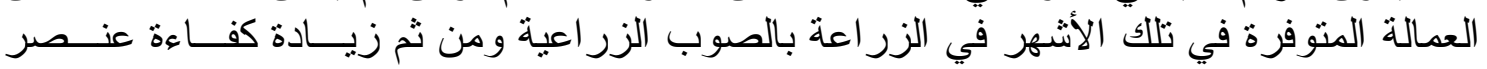
العمل.

r. التقلبات الموسمية للعمالة الثهرية لمحصول الخيار الثتوي في ظروف الحقل المكثوف:

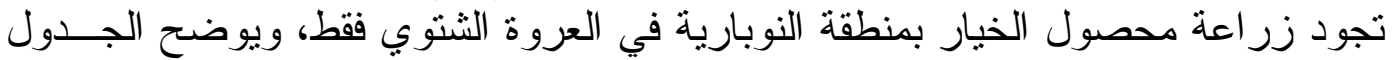

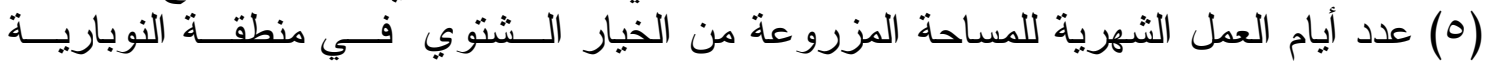

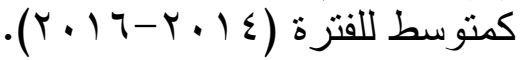

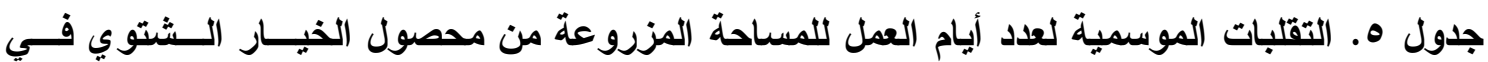

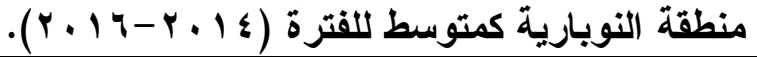

\begin{tabular}{|c|c|c|}
\hline الرقم القياسي الموسمي للعمالة ٪\% & أيام العمل للخيار الثتوي & الشهور \\
\hline $17 . \mathrm{r}$ & 1.90 & يناير \\
\hline 17.5 & 1.90 & فبر اير \\
\hline$T \varepsilon_{6} Y$ & $17 \leqslant$ TO. & 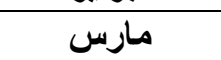 \\
\hline$r \leqslant \varepsilon, Y$ & $17 \leqslant$ YO. & إبريل \\
\hline$r \varepsilon 6 \varepsilon$ & $17 \leqslant$ YO & مايو \\
\hline • & $\cdot$ & يونيه - أكتوبر \\
\hline$\left|Y_{6}\right|$ & AYIYO & نوفمبر \\
\hline Mr.t & $r 19 \ldots$ & ديسمبر \\
\hline $1 \cdots$ & TVYTย, & المتوسط العام \\
\hline
\end{tabular}

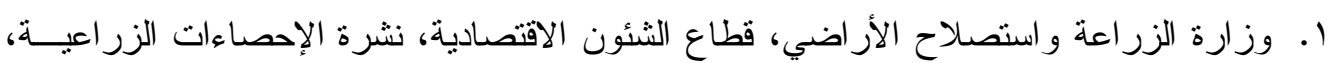

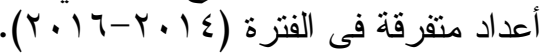

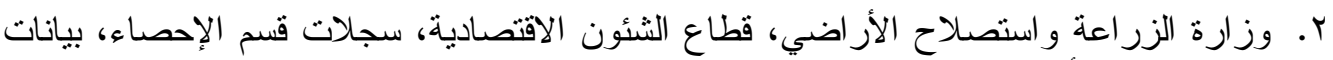

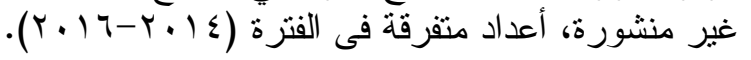

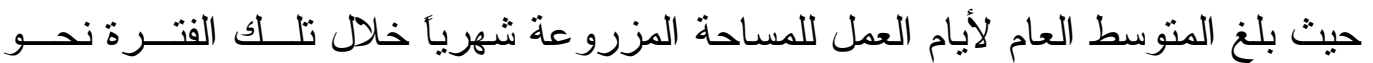

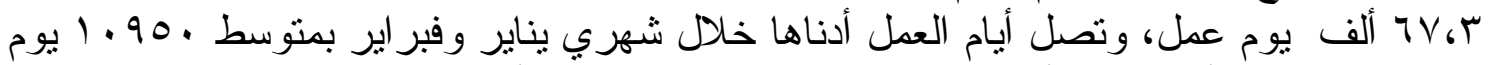

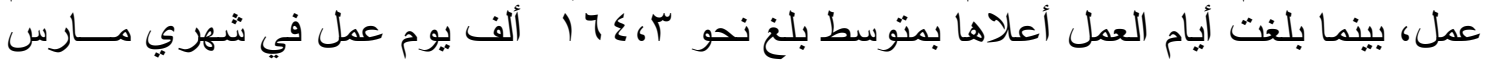

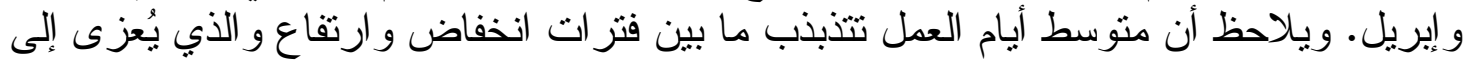

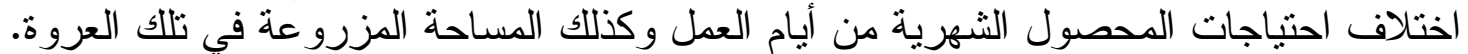

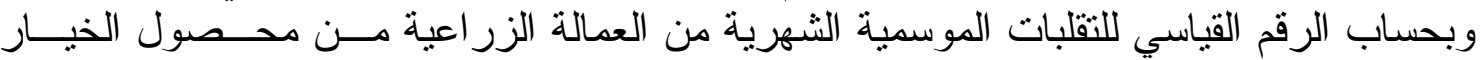

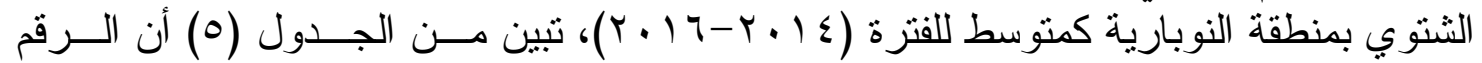

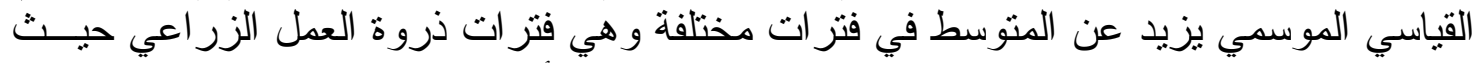

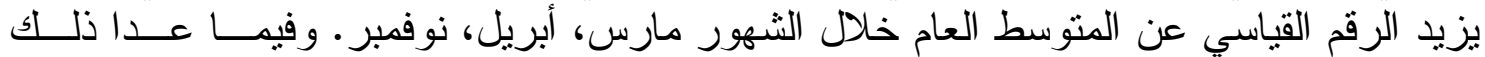

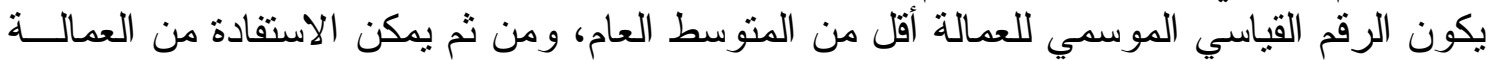

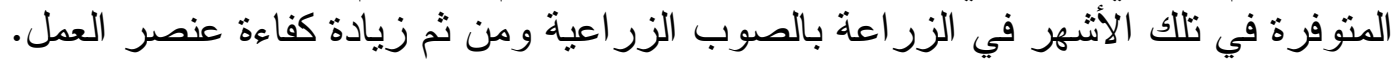

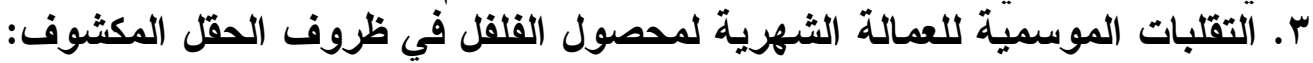



http://ajas.journals.ekb.eg/

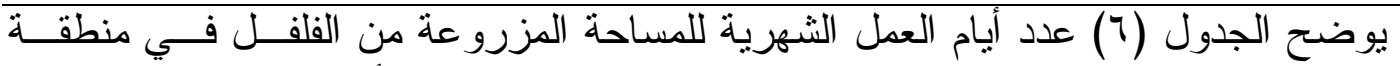

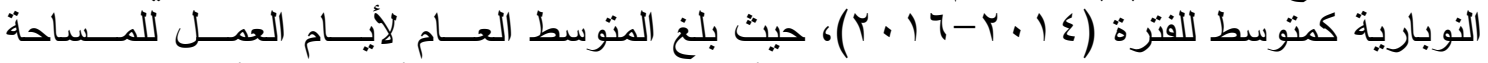

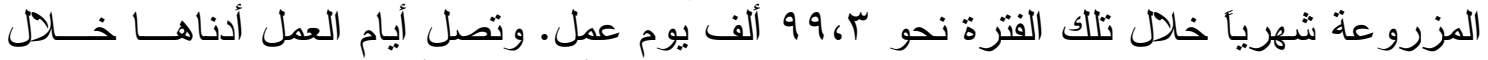

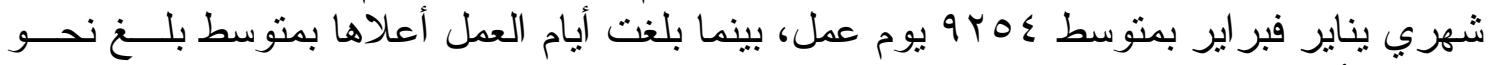

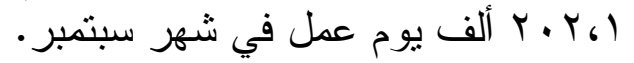

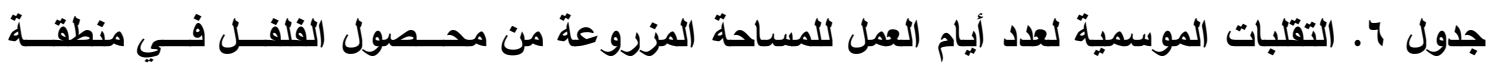

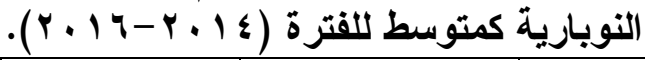

\begin{tabular}{|c|c|c|c|c|}
\hline الموسمي للعمالية القياسي & إجمالي أيام العمل للمساحة & ألفلقل النيلي العمل & أيام العمل القلقل & الشهور \\
\hline $96 r$ & $9 Y 0 \leq$ & $\cdot$ & qros & يناير \\
\hline 9.4 & 9405 & . & 9 9Y & فبر اير \\
\hline 11961 & $|T \wedge \wedge|$. & - & $|r \wedge \wedge|$. & مارس \\
\hline 11961 & $|r \wedge \lambda|$. & - & 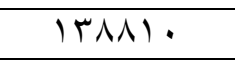 & إبريل \\
\hline $1 \varepsilon_{6}$ & $|r \wedge \wedge|$ & $\cdot$ & $|r \wedge \Lambda|$ & مايو \\
\hline$V Y_{6} \varepsilon$ & VoV9.60 & VOV9..0 & - & يونيه \\
\hline $1 \wedge r_{6}$ & $1 \wedge 1 \wedge 9 V$ & $1 \wedge 1 \wedge 9 V$ & - & يوليو \\
\hline$\left|V_{6}\right|$ & IVIV9Y & IVIVar & - & أغسطس \\
\hline$Y . T_{6} T$ & $r \cdot Y) \cdot \Lambda$ & $r \cdot Y l \cdot \Lambda$ & - & سبتمبر \\
\hline $17 r_{6} 9$ & 171717 & 171717 & • & أكتوبر \\
\hline 79.9 & $79 \leqslant .0$ & $\cdot$ & $79 \leq .0$ & نوفمبر \\
\hline $11_{6} 7$ & 110.1 & . & 110.1 & ديسمبر \\
\hline $1 \ldots$ & $994776 \%$ & - & - & المتوسط العام \\
\hline
\end{tabular}

المصدر : جمعت وحسبت من المات بيانات:

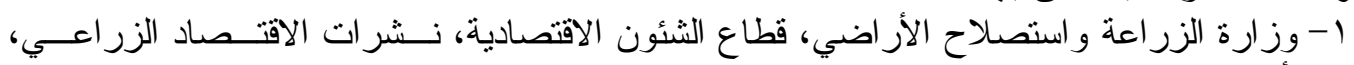

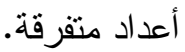

ץ- وز ارة الزر اعة واستصلاح الأر اضي، قطاع الثئون الافتصادية، سجلات قسم الإحصاء، بيانــات

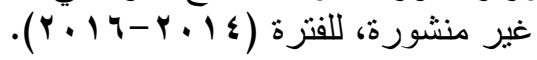

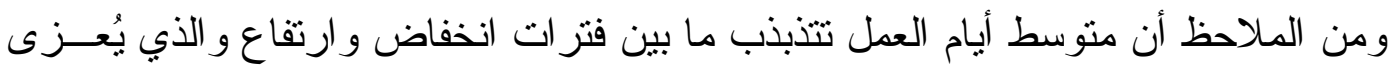

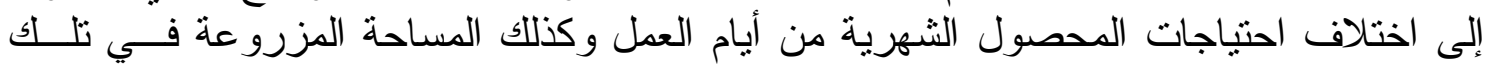

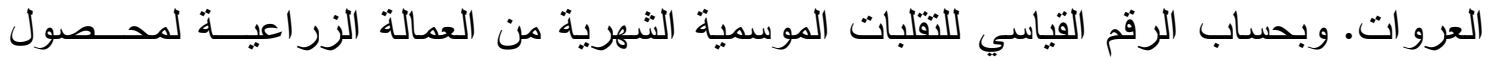

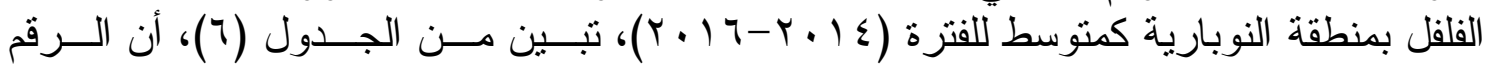

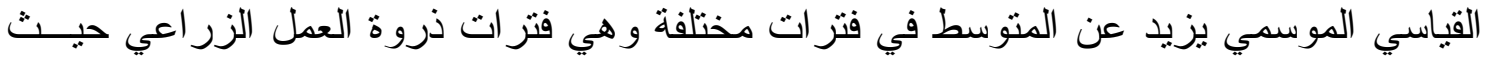

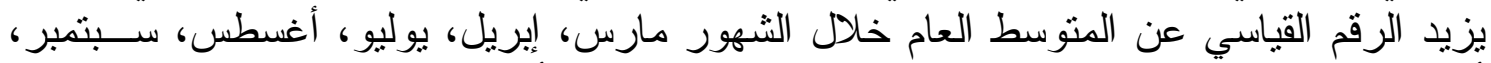

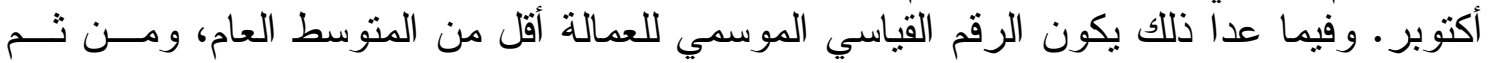

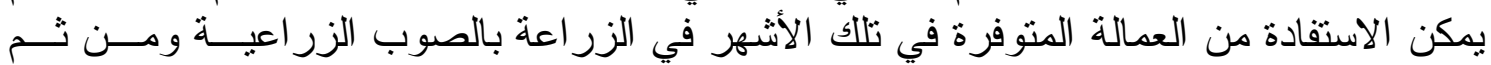

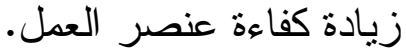

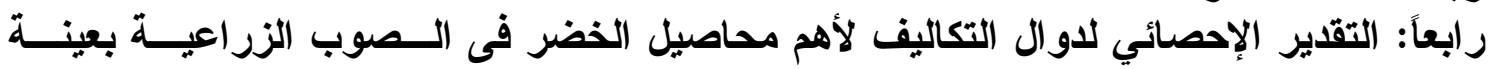

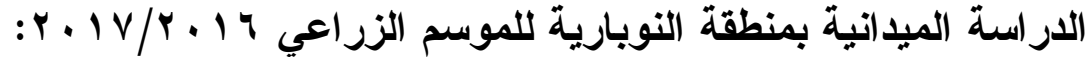

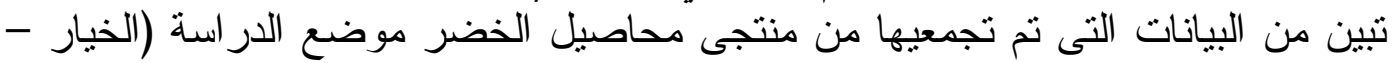
الطماطم - الففل) بعينة الدر اسة الميدانية بمنطقة النوبارية تجانس السعات الإنتاجية حيث منئ ينز اوح

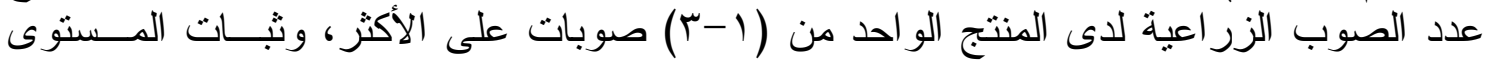




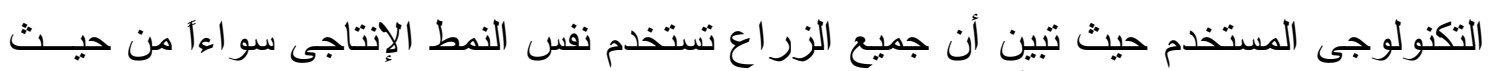

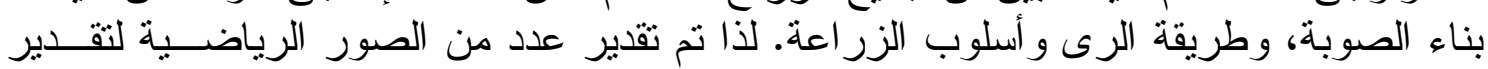

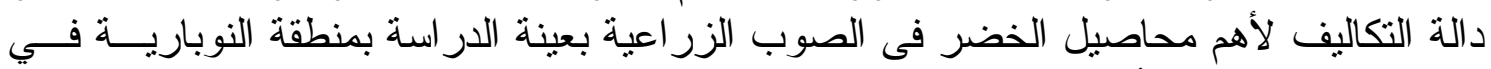

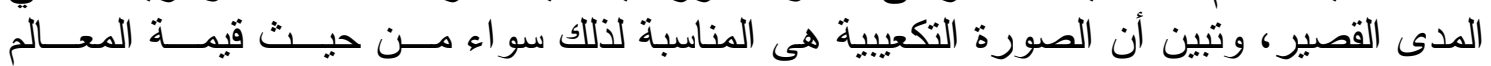

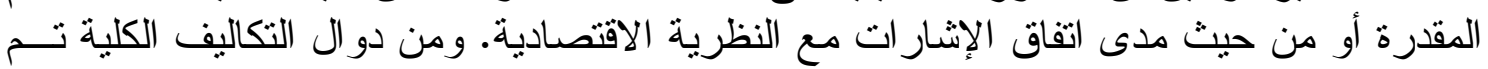

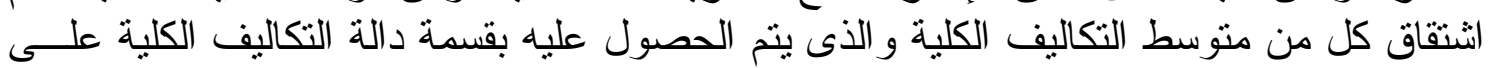

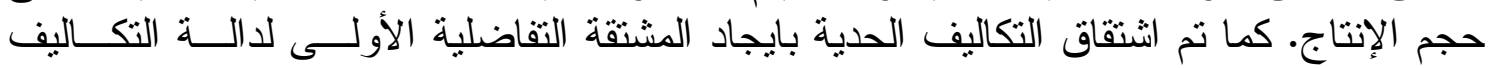

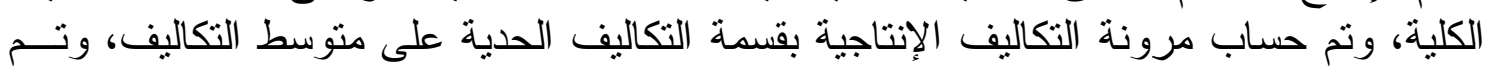

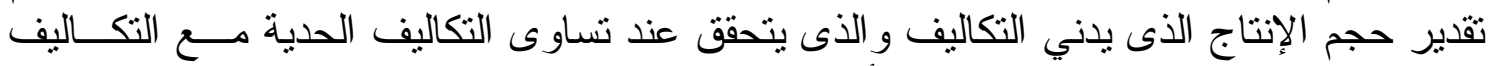

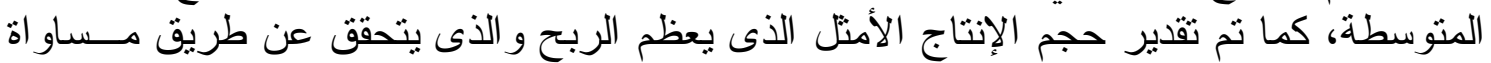

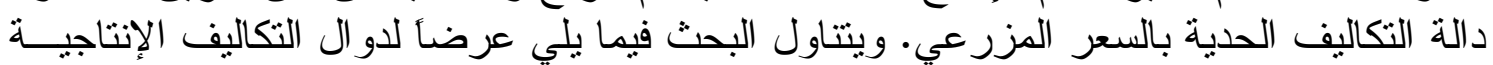

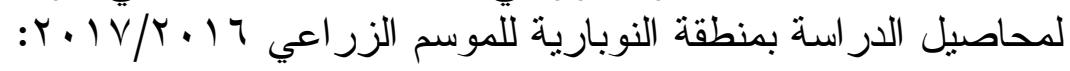

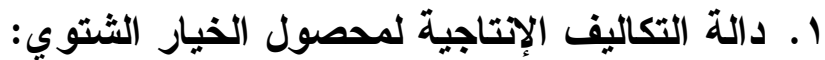

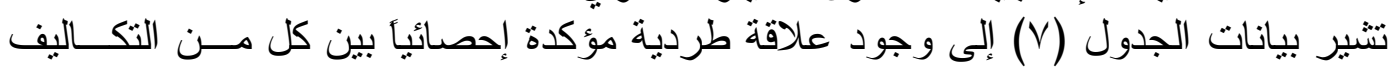

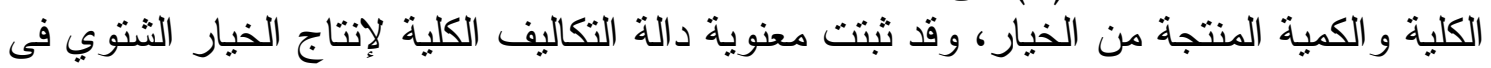

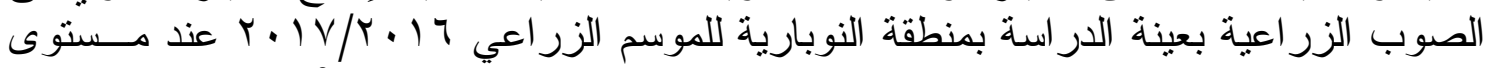

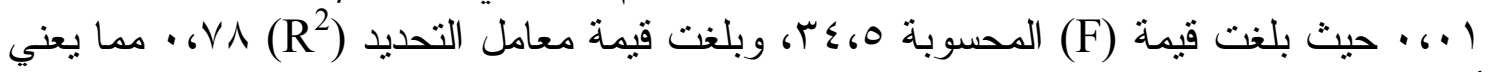

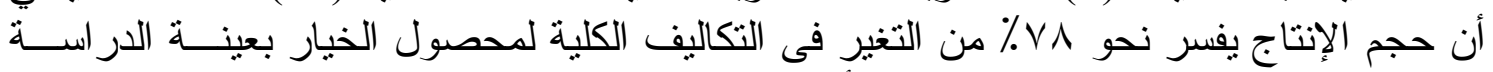

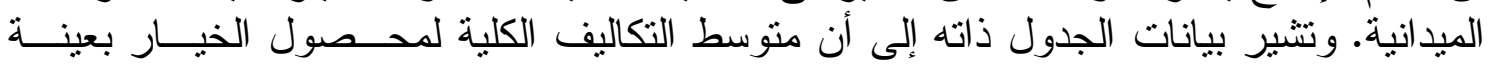

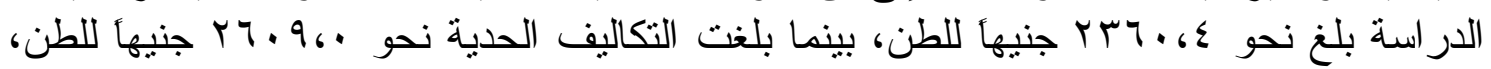

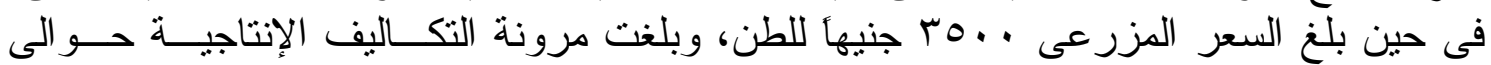

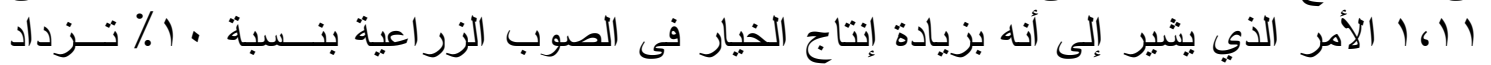

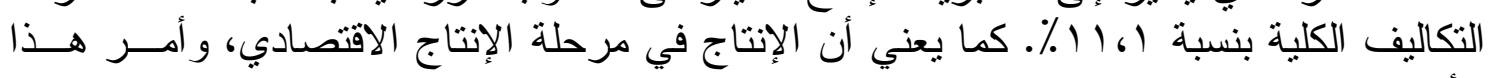

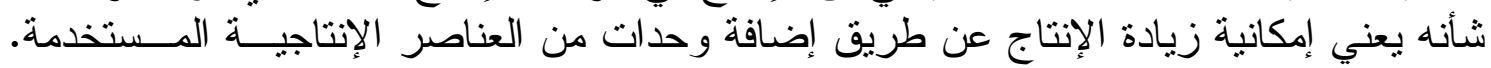

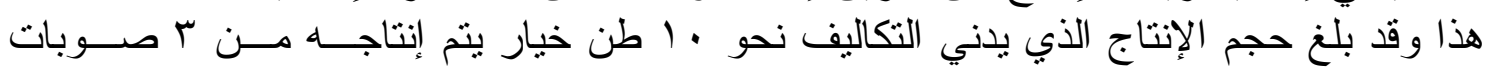

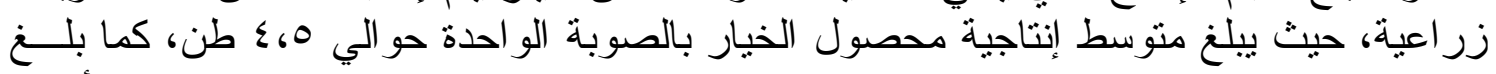

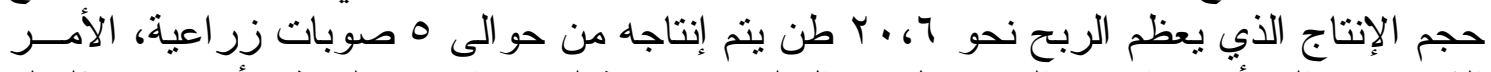

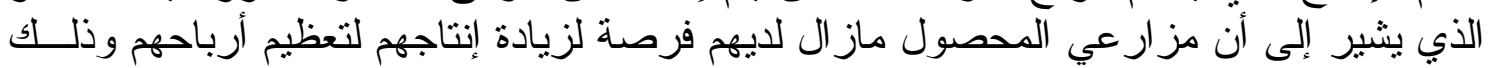

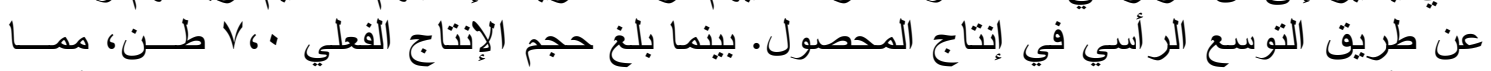

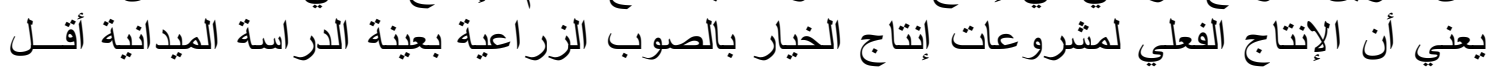

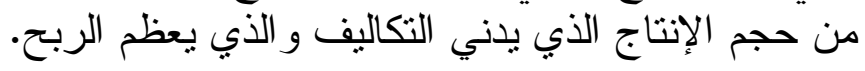

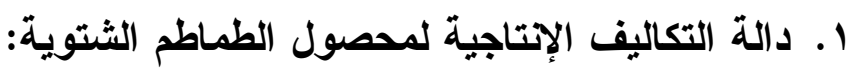

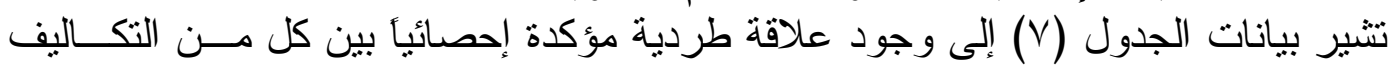

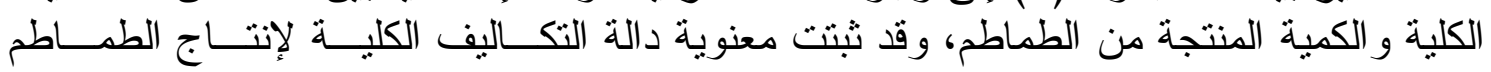

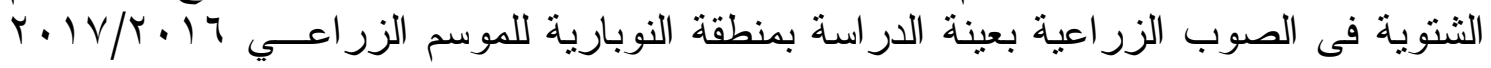

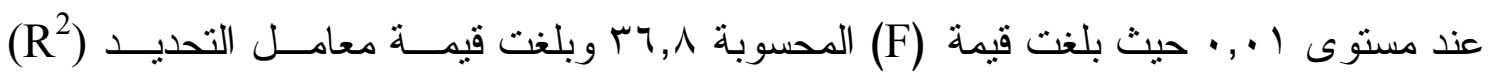

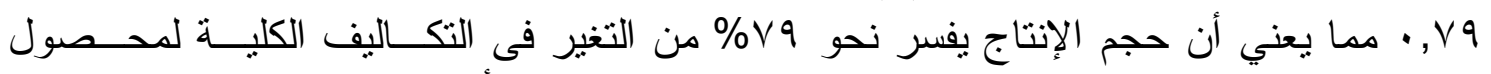

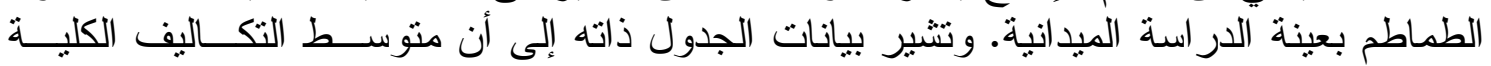

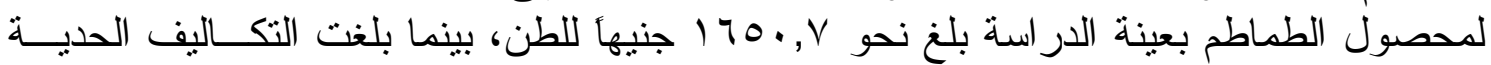

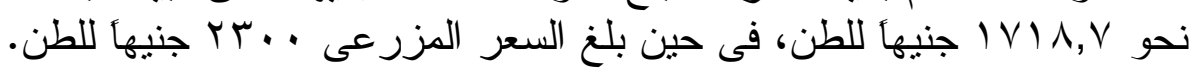


Website: www.aun.edu.eg/faculty_agriculture/journals_issues_form.php E-mail: ajas@aun.edu.eg

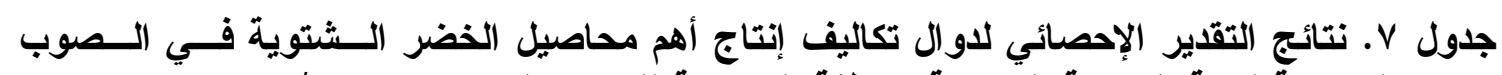

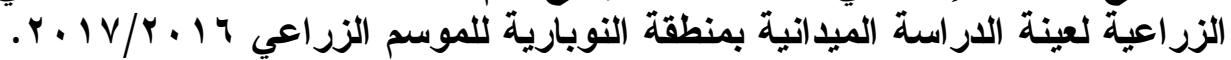

\begin{tabular}{|c|c|c|c|}
\hline معلمات الدالة المقدرة في الصورة التربيعية & الخيار & الطماطر & القلقل الملون \\
\hline a & $\begin{array}{l}70 \leq \cdot 60 \\
\left(Y_{6} T \Lambda\right)^{*}\end{array}$ & $\begin{array}{l}\wedge \wedge \wedge q_{6} 7 \\
\left(Y_{6} Y \wedge\right)^{*}\end{array}$ & $\begin{array}{l}\text { A Y . . T } \\
\left(Y_{6} T_{0}\right)^{*}\end{array}$ \\
\hline (معامل Q B (مع ) & $\begin{array}{l}-11 \Lambda_{6} r \\
\left(Y_{6} \wedge r^{*}\right)^{*}\end{array}$ & $\begin{array}{l}-1906 r \\
\left(Y_{6} \vee \wedge\right)^{*}\end{array}$ & $\begin{array}{l}-\sum Y Y_{6} T^{-} \\
\left(r_{6} q 1\right)^{* * *}\end{array}$ \\
\hline (معامل Q B (مع ) & $\begin{array}{c}r \cdot \cdot 6 r \\
(r \cdot 0 \Lambda)^{*} *\end{array}$ & $\begin{array}{c}906 \mathrm{~V} \\
(\Gamma ، \Sigma T)^{* * *}\end{array}$ & $\begin{array}{l}r \leq 0_{6} V \\
\left(Y_{6} V \wedge\right)^{*}\end{array}$ \\
\hline : متوسط حجم الانتاج الفعلي (بالطن) Q & $v_{6} \cdot$ & $1 \cdot 6 \cdot$ & $V_{6} 0$ \\
\hline Q: حجم الإنتاج المدني للتكاليف (بالطن) & 0.71 & $7 ، \wedge$ & $0, \wedge$. \\
\hline : حجم الإنتاج المعظم للأرباح (بالطن) Q & $\Lambda_{6}(7)$ & $1 r_{6} \cdot \varepsilon$ & $1 \cdot 6 \cdot$ \\
\hline MC & $r \wedge T \leq 60$ & $|V| \Lambda_{6} V$ & Trtrgr \\
\hline AC متوسط التكاليف (بالجنيه للطن) & KYAV,O & $170 \cdot, \mathrm{V}$ & TOYT, \\
\hline P: السعر المزرعي (بالجنيه للطن) & ro.. & r... & $\leqslant 0 \ldots$ \\
\hline C & 1,45 & $16 \cdot \varepsilon$ & 1649 \\
\hline $\mathrm{R}^{2}$ &. & $.6 \vee 9$ & .691 \\
\hline $\mathrm{F}$ & rq.० & $r 4_{6}$ & $00, V$ \\
\hline
\end{tabular}

حيث: a ، B B معالم دالة تكاليف إنتاج الخضر موضع الدر اسة في المدى القصير لعينة الدر اسة الميدانيــة

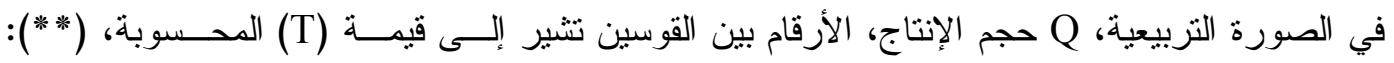

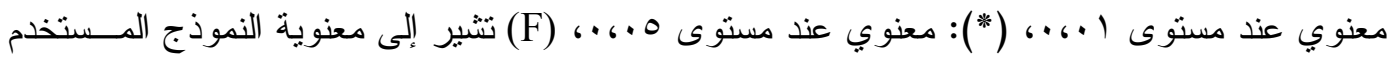

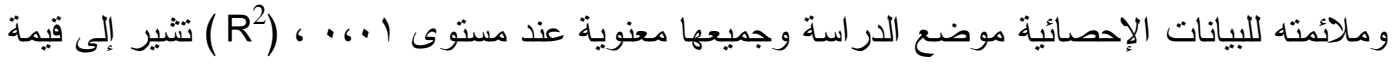
معامل التحديد. المصدر: جمعت وحسبت من نتائج التحليل الاحصائي لبيانات عينة الدر اسة الميدانية بمنطقة النوبارية للموســ

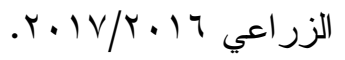

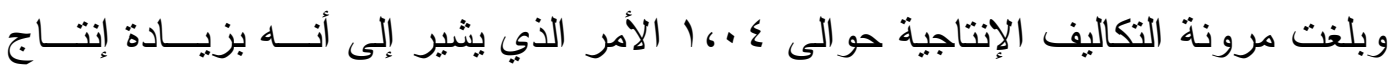

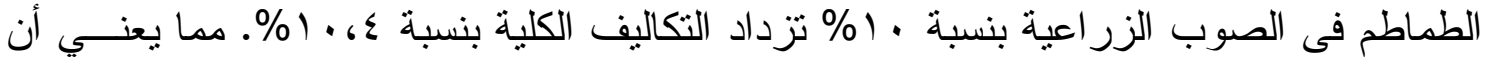

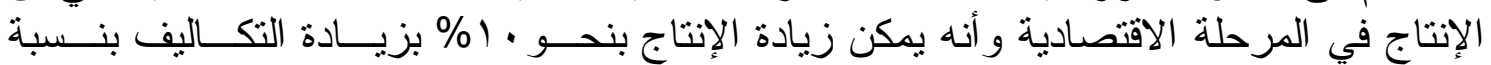

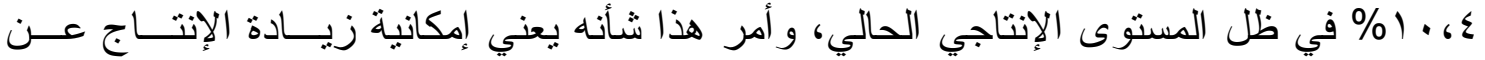

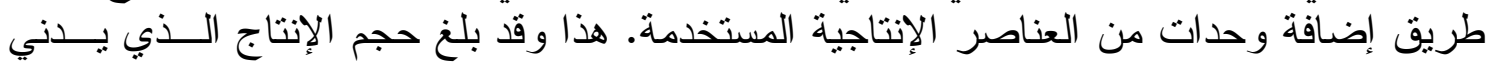

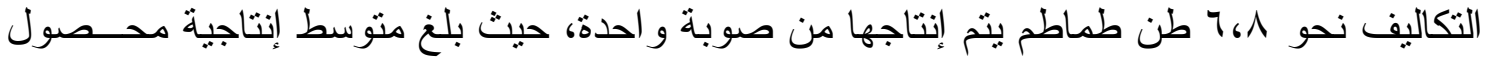

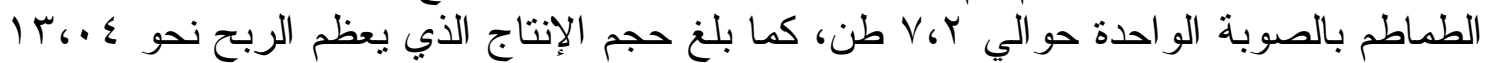

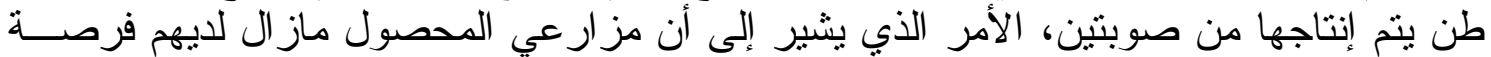

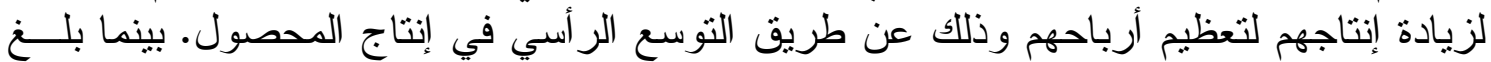

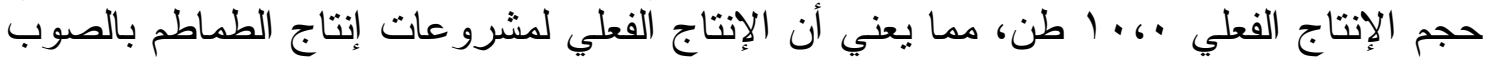


الزر اعية بعينة الدر اسة الميدانية أكبر من حجم الإنتاج الذي يدني التكاليف و أقل من حجم الإنتاج الأبي يعظم الربح.

\section{Y. ب دالة التكاليف الإتتاجية لمحصول القلقل الملون الشتوي:}

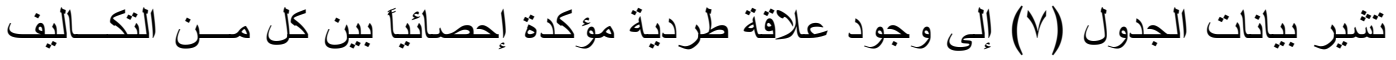

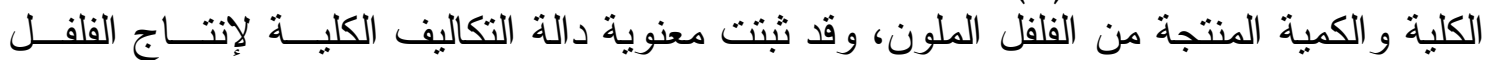

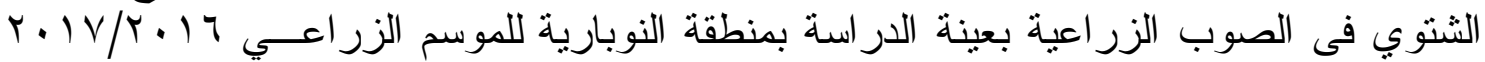

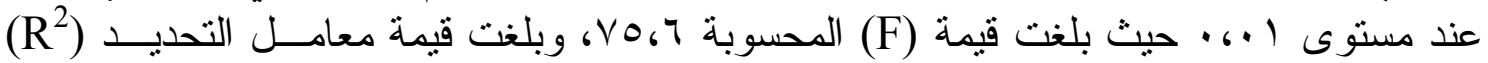

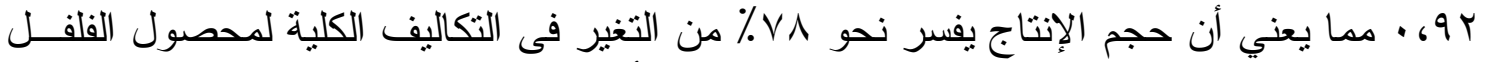

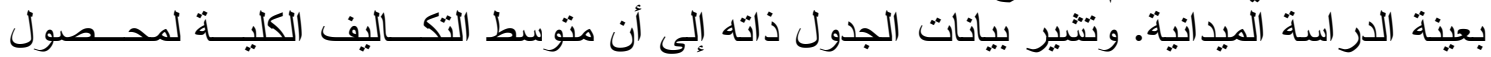

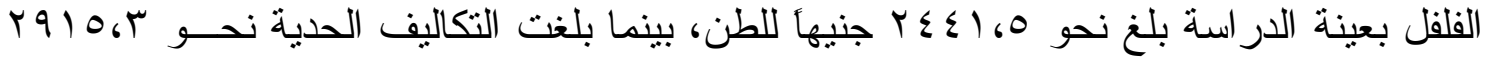

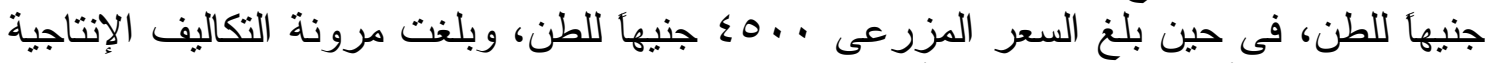

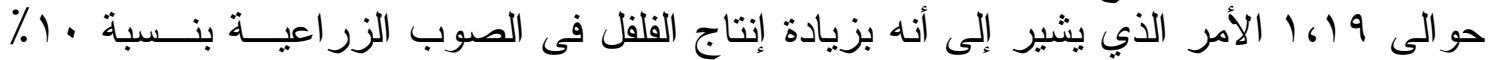

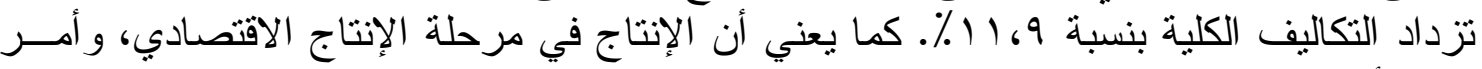

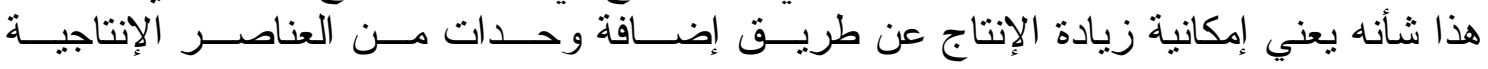

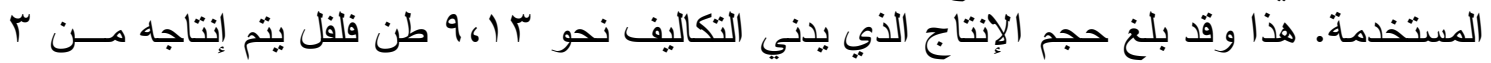

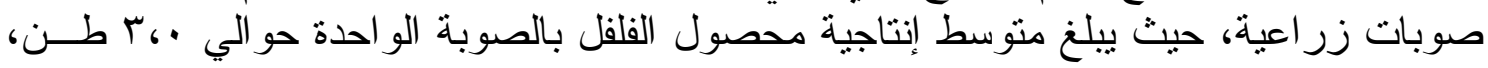

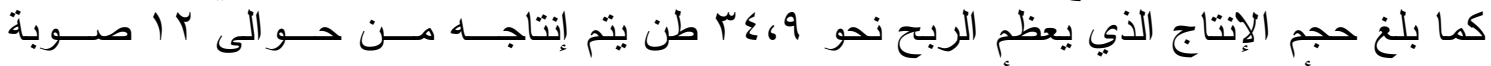

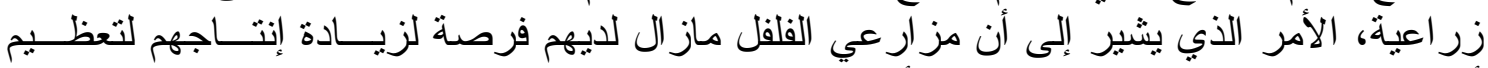

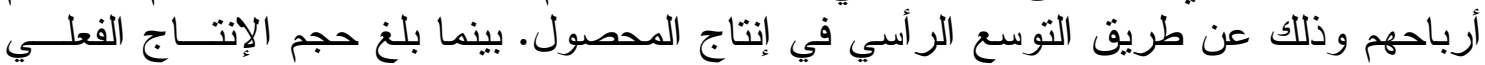

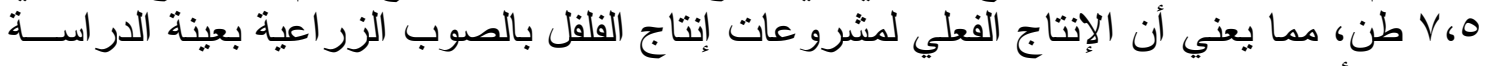

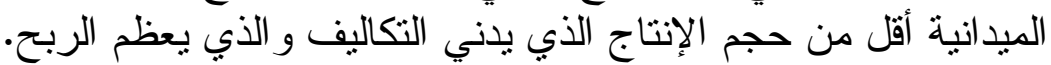

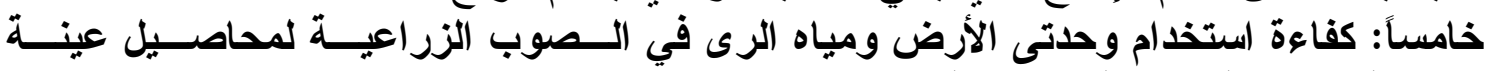

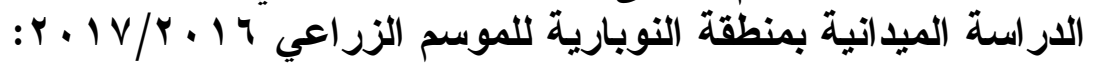

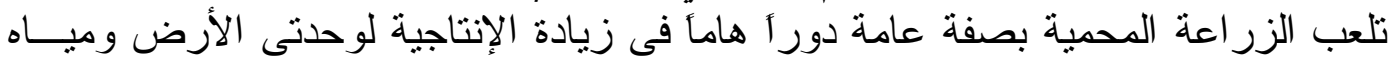

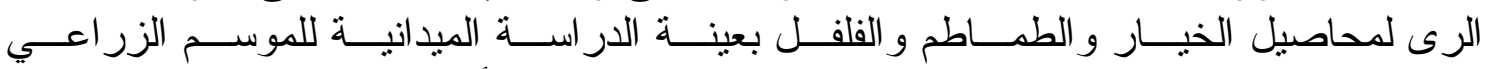

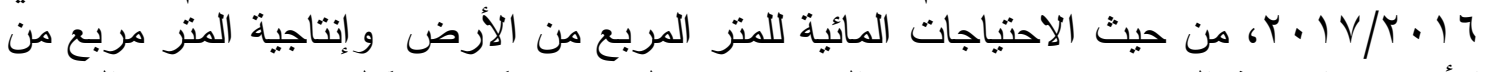

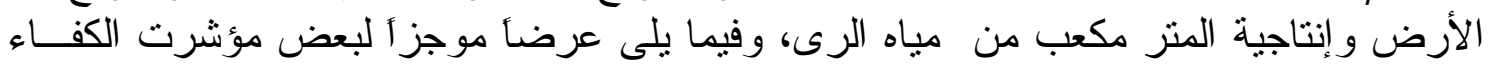
الاقتصادية لمحاصبل عينة الدر اسة:

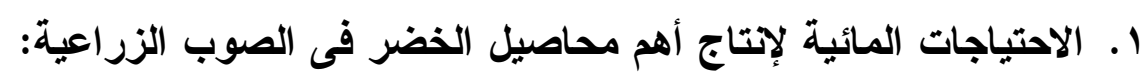

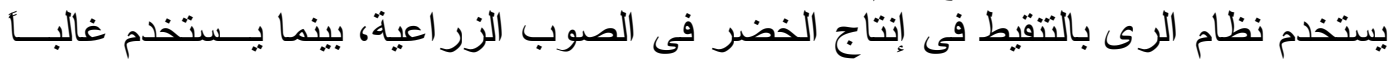

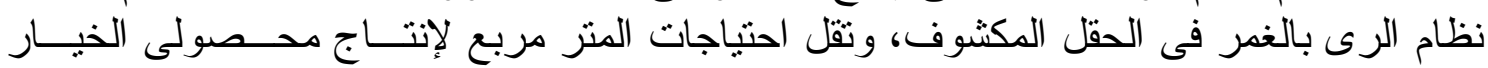

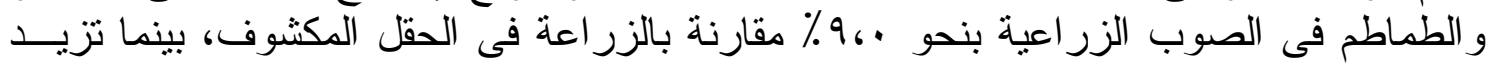

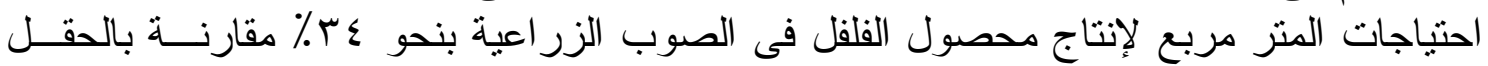

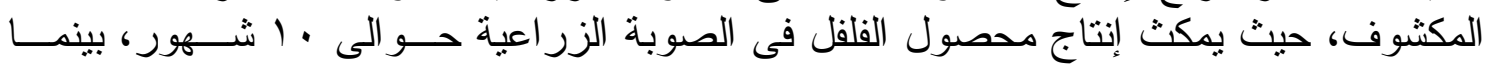

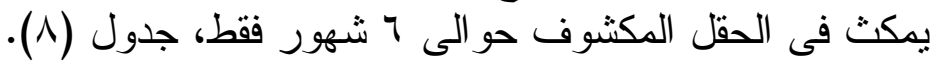

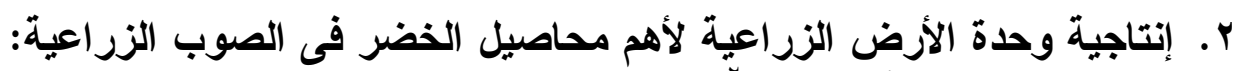

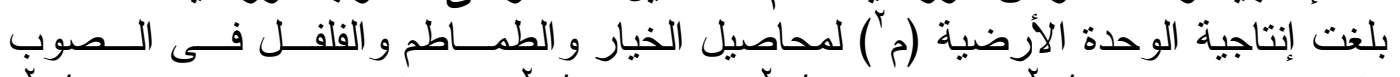

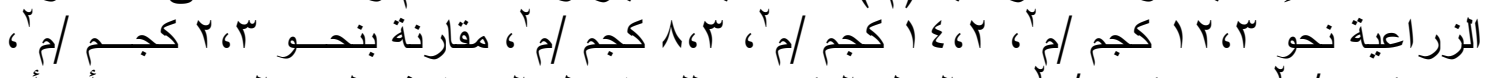

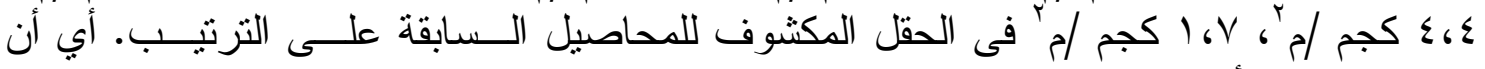

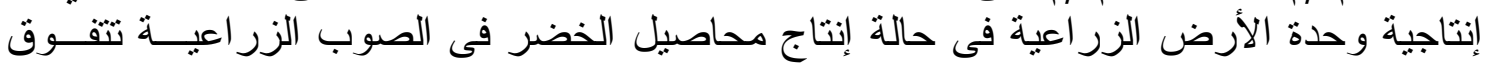


Website: www.aun.edu.eg/faculty_agriculture/journals_issues_form.php E-mail: ajas@aun.edu.eg

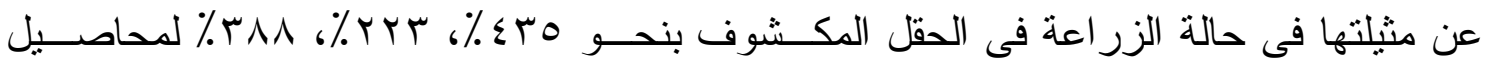

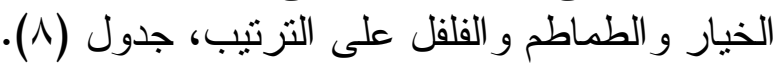

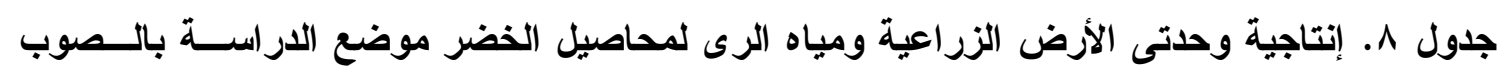

\begin{tabular}{|c|c|c|c|}
\hline الفلقل الثتوى & الطماطم الثتوى & الخيار الثتوى & البيان \\
\hline & & & 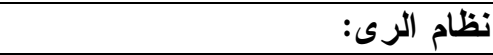 \\
\hline غمر & غمر & غمر & حقل مكشوف: \\
\hline 7.7 & $1 V_{60}$ & 96. & إنتاجية الفدان بالطن \\
\hline $174 \mathrm{~V}$ & IN.Y & IVVI & الاحتباجات المائية للفان م \\
\hline تتقيط & تتقيط & تتقبط & صوبة زراعية: \\
\hline$r \cdot . \cdot$ & A. .6. & 0.6. & إنتاجية الفدان صوب بالطن \\
\hline rr.. & $17 \varepsilon$. & 171. & الاحتباجات المائية للفدان صوب م \\
\hline & & & الاحتياجات المائية ( م / / مץ ): \\
\hline . ،乞 & $.6 \leqslant 0$ & . ، $\Sigma \varepsilon$ & حقل مكثوف \\
\hline .600 & .، & •، & صوبة زر اعية \\
\hline $.61 \leqslant$ & $\cdot \cdots \varepsilon-$ & $\cdot 6 \varepsilon-$ & مقدار الفرق: م \\
\hline$r \varepsilon 61$ & $\Lambda_{6} 9$ & 961 & $\%$ \\
\hline & & & إنتاجية وحدة الأرض ( كجم /م ) ): \\
\hline $1 . \mathrm{V}$ & $\varepsilon_{6} \varepsilon$ & T.T & حقل مكثوف \\
\hline$\Lambda_{6} \mathrm{~T}$ & $1 \varepsilon_{6 r}$ & IT,T & صوبة زر اعية \\
\hline 767 & 961 & 1. & مقدار الزيادة: كحم /2 \\
\hline rAM & rTr & \&ro & $\%$ \\
\hline & & & إنتاجية وحدة المياه ( كجم / مץr): \\
\hline$\varepsilon$ & $9 . \mathrm{V}$ & 0,1 & حقل مكشوف \\
\hline 14.7 & $\varepsilon \Lambda_{6} \varepsilon$ & r1.1 & صوبة زر اعية \\
\hline 9,7 & $r 961$ & ry & الفرق: كحم /2 \\
\hline$r \varepsilon$. & $\left.\varepsilon \cdot T_{6}\right)$ & $0 . \Lambda_{6} \Lambda_{1}-1010$ & $\%$ \\
\hline
\end{tabular}

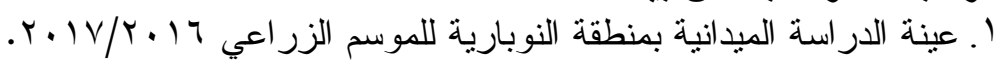

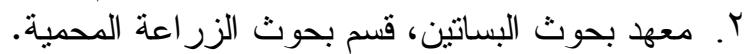

rا. الجهاز المركزي للتعبئة العامة والإحصاء، نثرة المو ارد المائية والري، موقع الجهاز على شبكة الانترنت.

\section{r. إنتاجية وحدة مياه الرى لأهم محاصيل الخضر فى الصوب الزراعية:}

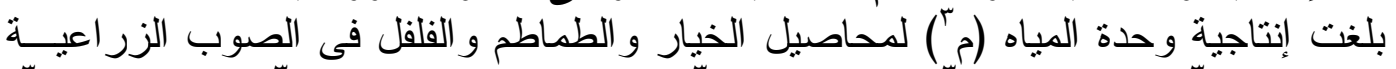

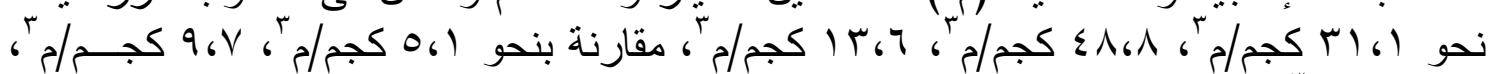

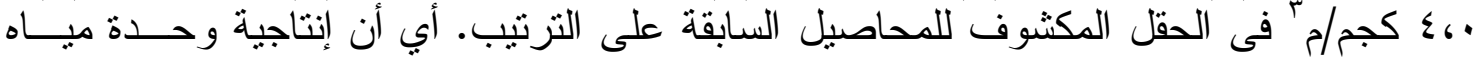

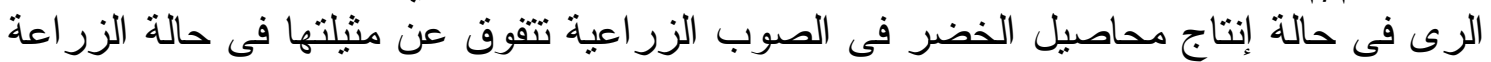

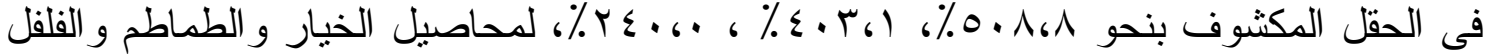

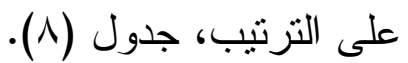

سادساً: المشكلات التى تولى اجه منتجى محاصيل الخضر في الصوب الزراعية بعينة الاراسة:

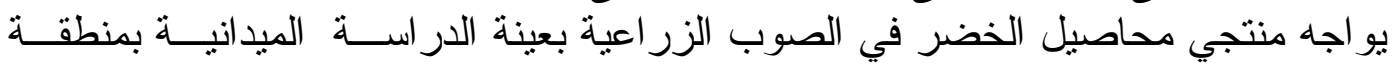

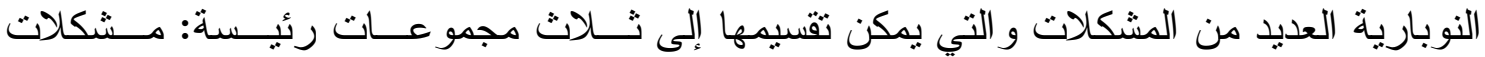


هيكلية، ومشكلات سلوكية، ومشكلات فنية. وقد تبين من نتائج التحليل الإحصائي أن المـشكلات

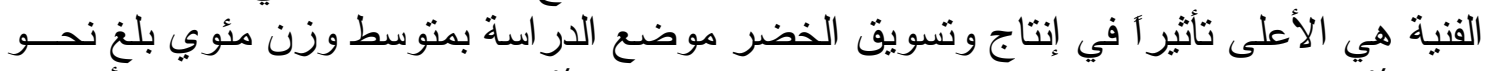

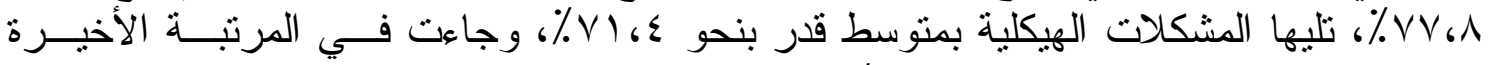

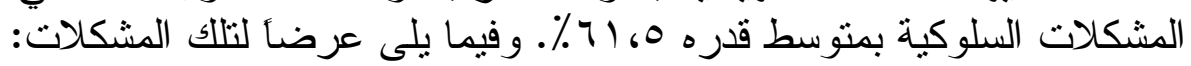

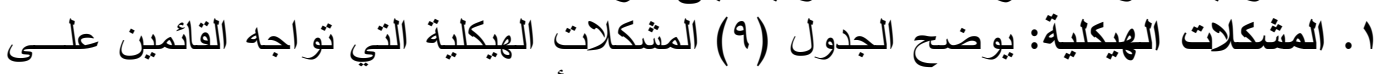

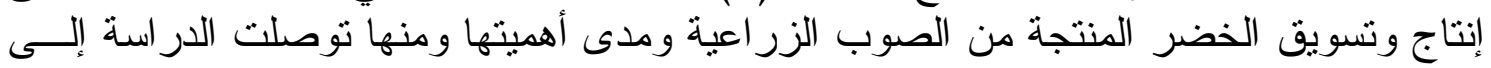
ما يلي:

احتلت مشكلة تذبذب الأسعار وعدم وجود معلومات تسويقية كافية الترتيب الأول من

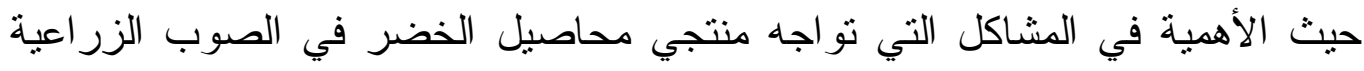

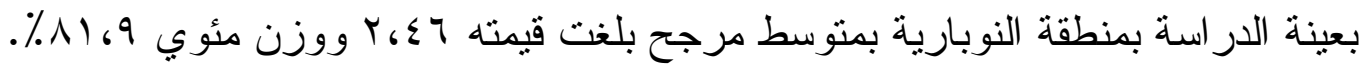
يلي ذلك في الأهمية مشكلة استغلال التجار للمزارعين، حيث جاءت في الترتيب الثاني لمجموعة المشاكل التي تواجه منتجي محاصيل الخضر في الصوب الزربه اعية بعينة

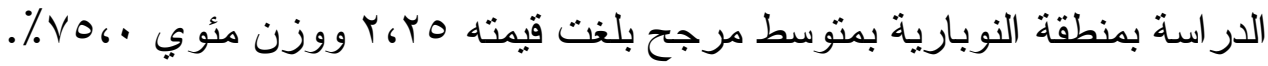
أما مشكلة عدم كفاية القرض الممكن الحصول عليه فقد احتلت الترتيب الثالث من حيث

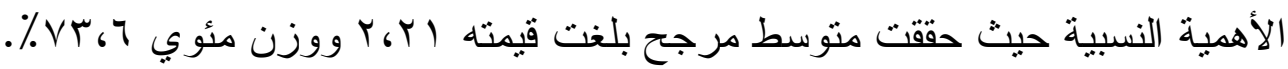
وجاءت مشكلة زيادة العرض من الخضر في بعض المواسم في الترتيب الرابع لمجموعة

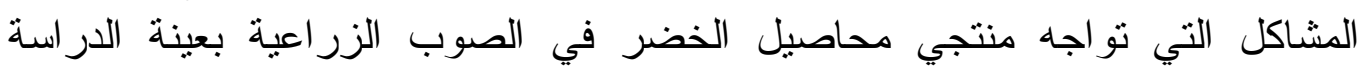

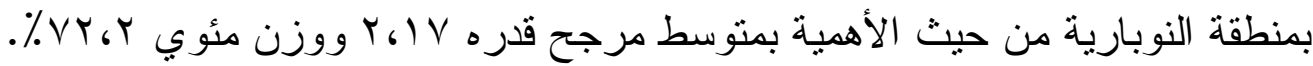
أما مشكلة انتشار الأمر اض والأفات فقد جاءت في الترتيب الخامس من حيث الأهمية

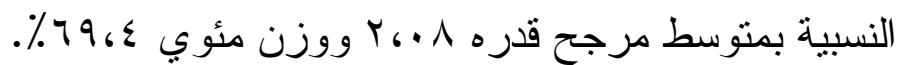

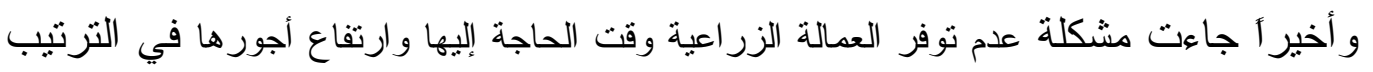

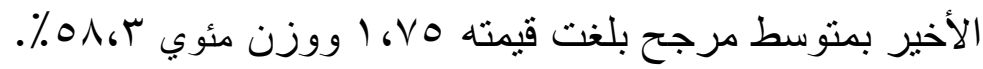


Website: www.aun.edu.eg/faculty_agriculture/journals_issues_form.php E-mail: ajas@aun.edu.eg

جدول 9.

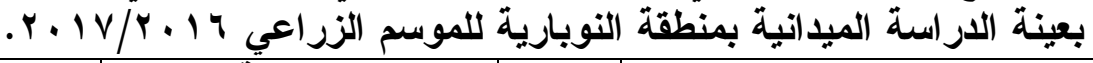

\begin{tabular}{|c|c|c|c|c|c|c|c|}
\hline \multirow[b]{2}{*}{ 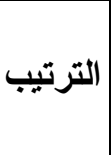 } & \multirow{2}{*}{$\begin{array}{c}\text { المئوين } \\
\text { \% }\end{array}$} & \multirow{2}{*}{ المرجح } & \multicolumn{3}{|c|}{ الاستجابة } & \multirow[b]{2}{*}{ والنسبة } & \multirow[b]{2}{*}{ المشكلات } \\
\hline & & & 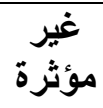 & 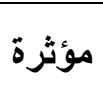 & مؤثرة & & \\
\hline \multirow{2}{*}{0} & \multirow{2}{*}{7965} & \multirow{2}{*}{$r_{6} \cdot 1$} & $r \cdot$ & 0. & $\varepsilon \cdot$ & $\varepsilon$ & \multirow{2}{*}{ انتشار الأمر اض والآفات } \\
\hline & & & ro & $\sum 1, V$ & Tr.T & $\%$ & \\
\hline \multirow{2}{*}{7} & \multirow{2}{*}{$0 \Lambda_{6} \mathrm{r}$} & \multirow{2}{*}{1600} & 7. & $r \cdot$ & $r \cdot$ & $\varepsilon$ & \multirow{2}{*}{ وارتفاع توفر العمالة الزراعية وقت الحاجة إليها } \\
\hline & & & 0. & To & To & $\%$ & \\
\hline \multirow{2}{*}{1} & \multirow{2}{*}{11,9} & \multirow{2}{*}{$r_{6} \leqslant 7$} & 1. & $\leqslant 0$ & 70 & $\varepsilon$ & \multirow{2}{*}{ تَبويقية كافية الأسعار وعدم وجود معلومات } \\
\hline & & & $\Lambda_{6} \mathrm{~T}^{2}$ & $r V_{6} 0$ & $0 \leqslant 6 Y$ & $\%$ & \\
\hline \multirow{2}{*}{ r } & \multirow{2}{*}{ vo } & \multirow{2}{*}{ r.ro } & ro & $\varepsilon$ & 00 & $\varepsilon$ & \multirow{2}{*}{ استغلال التجار للمزارعين } \\
\hline & & & $r \cdot 6 \Lambda$ & Tr.r & $\sum 0,1$ & $\%$ & \\
\hline \multirow{2}{*}{$r$} & \multirow{2}{*}{ 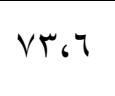 } & \multirow{2}{*}{$r_{6} r_{1}$} & ro & $\leqslant 0$ & 0. & $\varepsilon$ & \multirow{2}{*}{ عدم كفاية القرض الممكن الحصول عليه } \\
\hline & & & $r \cdot 6 \Lambda$ & rV.O & $\sum 16 V$ & $\%$ & \\
\hline \multirow{2}{*}{$\varepsilon$} & \multirow{2}{*}{ VY, } & \multirow{2}{*}{ r. IV } & ro & 0. & $\leqslant 0$ & $\varepsilon$ & \multirow{2}{*}{ زيادة العرض من بعض الخضر في بعض } \\
\hline & & & $r \cdot 6 \Lambda$ & $\Sigma 16 V$ & $r_{V} V_{0}$ & $\%$ & \\
\hline - & $V 1, \varepsilon$ & T.1 $\varepsilon$ & - & - & - & - & المتوسط \\
\hline
\end{tabular}

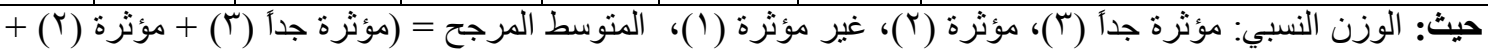

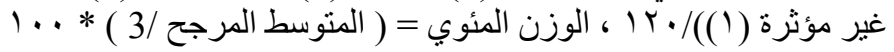

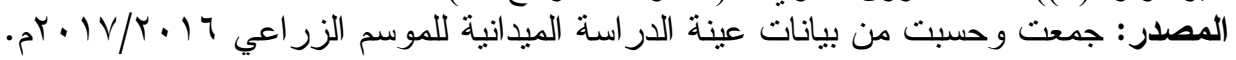

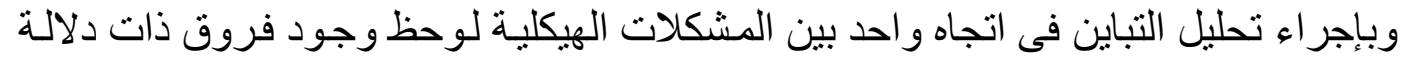

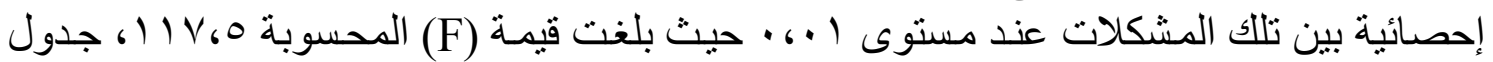

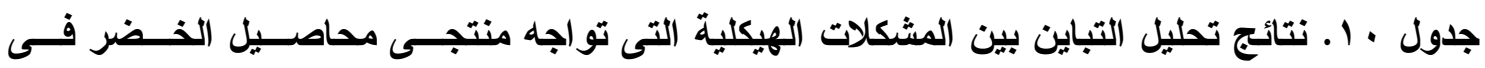

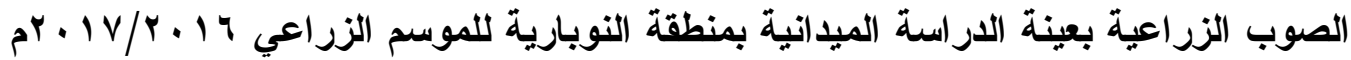

\begin{tabular}{|c|c|c|c|c|}
\hline قلمسمة (F) & متوسط مجموع مربعات & مجموع مربعات & درجات الحرية & مصدر الاختلاف \\
\hline$* *(1 \mid \vee 60)$ & YT، & 1.7965 & 0 & بين المشكلات \\
\hline - & $16 \wedge r$ & $\Lambda \cdot \Lambda_{6} 7$ & $\leqslant \leqslant 0$ & داخل المشكلات \\
\hline - & - & $I A v V_{6} \Lambda$ & $\leqslant 0$. & المجموع \\
\hline
\end{tabular}

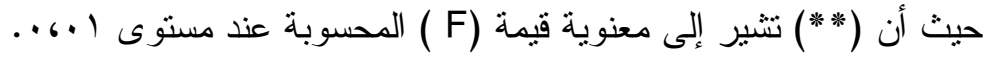
المصدر: جمعت وحسبت من بيانات عينة الدر اسة المبدانية.

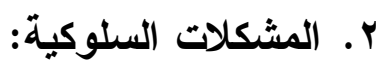

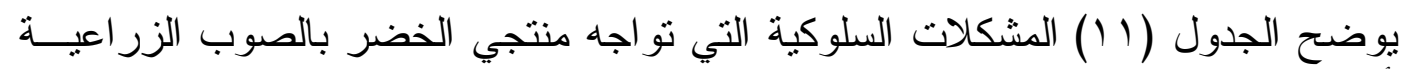
ومدى أهيتها ومنها تبين ما يلي: الجيكان

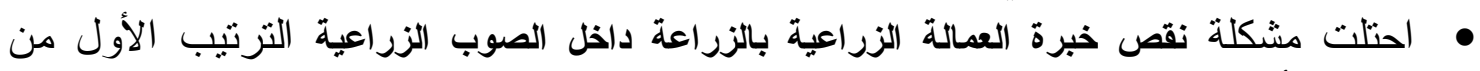

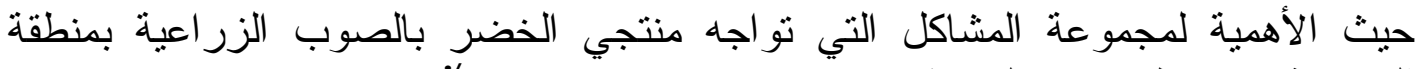

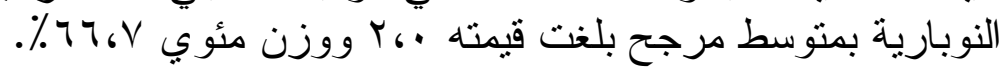



http://ajas.journals.ekb.eg/

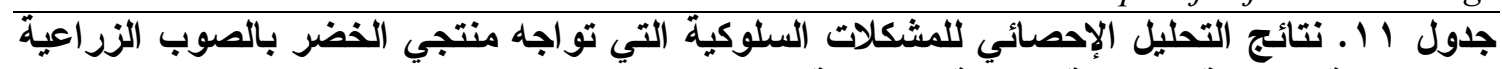

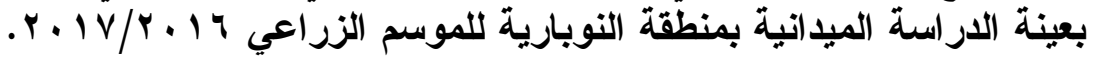

\begin{tabular}{|c|c|c|c|c|c|c|c|}
\hline \multirow[b]{2}{*}{ 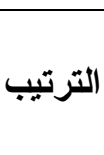 } & \multirow{2}{*}{ 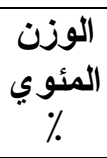 } & \multirow[b]{2}{*}{ المرجح } & \multicolumn{3}{|c|}{ الاستجابة } & \multirow[b]{2}{*}{ و النسبة } & \multirow[b]{2}{*}{ المشكلات } \\
\hline & & & مؤثيرة & مؤثرة & مؤثرة & & \\
\hline \multirow{2}{*}{1} & \multirow{2}{*}{$74 . \mathrm{V}$} & \multirow{2}{*}{ r } & $\leqslant 0$ & $r$. & $\leqslant 0$ & $\varepsilon$ & \multirow{2}{*}{ قص خبرة العمالة الزراعية بالزراعة داخل الصوب الزراعية } \\
\hline & & & $r V_{6} O$ & ro & $r V_{6} O$ & $\%$ & \\
\hline \multirow{2}{*}{ r } & \multirow{2}{*}{$7 \varepsilon$ ، } & \multirow{2}{*}{1.94} & $\leqslant \varepsilon$ & $\varepsilon \cdot$ & ry & $\varepsilon$ & \multirow{2}{*}{ كثرة الاجراءات اللازمة للحصول على قرض } \\
\hline & & & r4.V & TrGr & $r$. & $\%$ & \\
\hline \multirow{2}{*}{ r } & \multirow{2}{*}{$\varepsilon 0,4$} & \multirow{2}{*}{1.74} & $v \cdot$ & ro & To & $\varepsilon$ & \multirow{2}{*}{ قص المعرفة بالطرق المثلى للتسويق } \\
\hline & & & $0 \Lambda_{6} r$ & $r \cdot \sigma \Lambda$ & $r \cdot ، \Lambda$ & $\%$ & \\
\hline - & 71.01 & 1610 & - & - & - & - & المتوسط \\
\hline
\end{tabular}

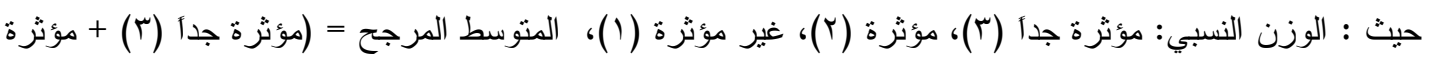

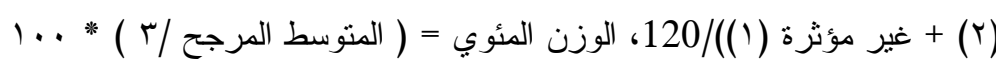

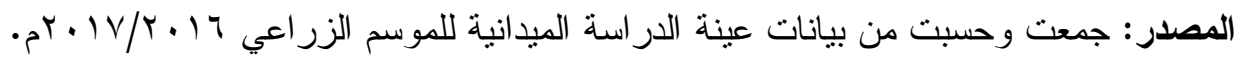

• يلي ذلك في الأهمية مشكلة كثرة الاجراءات اللازمة للحصول على قرض، حيث حققت التزتيب

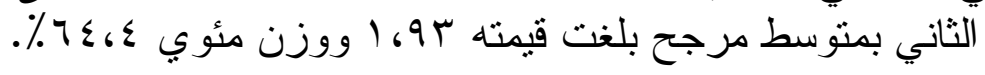
• أما مشكلة نقص المعرفة بالطرق المثلى لتسويق الخضر فقد جاءت في الترتئه التيب الأخير لمجموعة

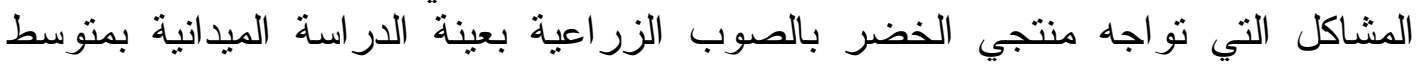

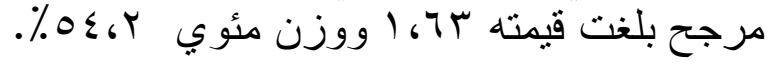

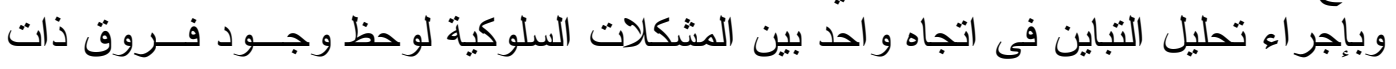

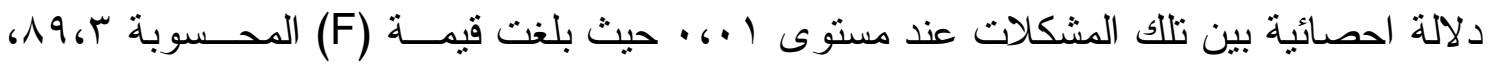
جدول رقم (r (I)).

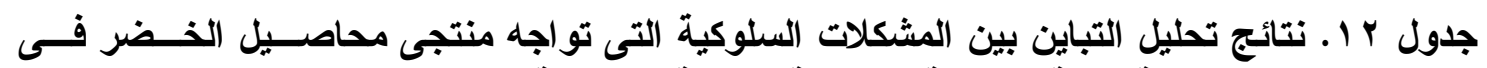

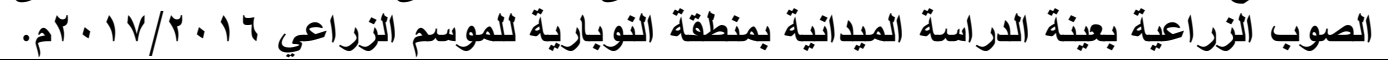

\begin{tabular}{|c|c|c|c|c|}
\hline قيمة (F) المحسوبة & متوسط مجموع مربعات الاحررافات & مجموع مربعات الاحر |فات & درجات الحرية & مصدر الاختلاف \\
\hline$* *(\wedge q, r)$ & $\varepsilon \cdot$. $r$ & $\Lambda \cdot . \varsigma$ & $r$ & بين المشكلات \\
\hline & $.6 \leqslant 0$ & $\vee \Lambda_{6} \wedge$ & IVV & داخل المشكلات \\
\hline & & $1096 r$ & $1 v 9$ & المجموع \\
\hline
\end{tabular}

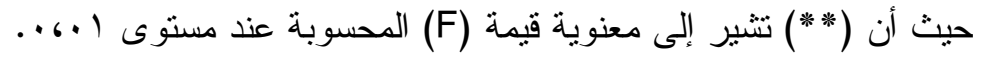
المصدر : جمعت وحسبت من بيانات عينة الدر اسة الميد النية.

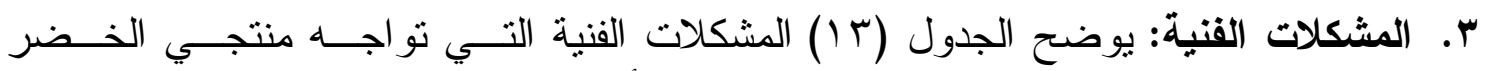

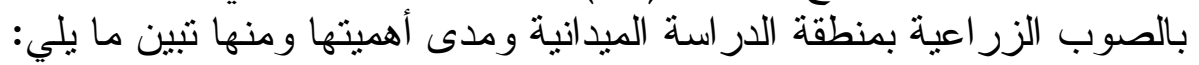

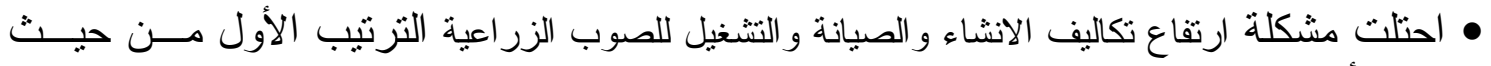

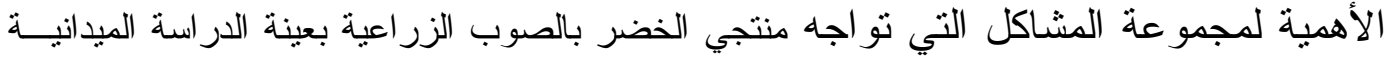

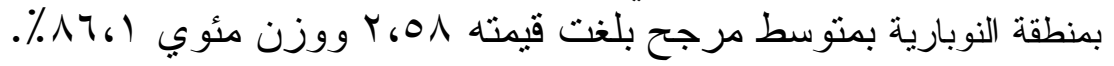

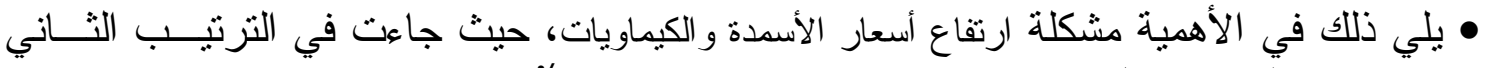

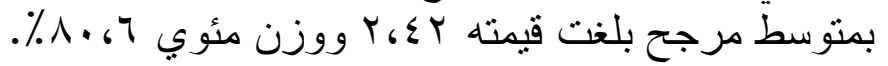


Website: www.aun.edu.eg/faculty_agriculture/journals_issues_form.php E-mail: ajas@aun.edu.eg

• أما مشكلة ارتفاع تكاليف الخدمات التسويقية المقدمة للزراع و انخفاض جودتها فقد جاءت في التزتيــبـ

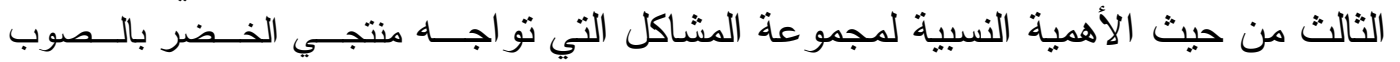

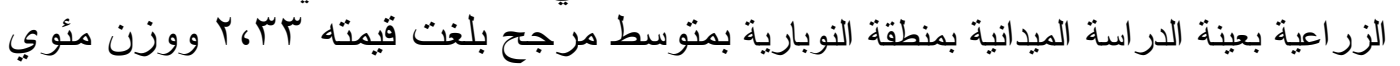

$\% \vee V_{6} \wedge$

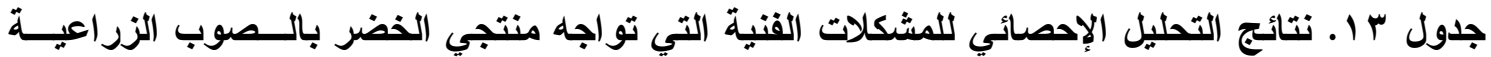

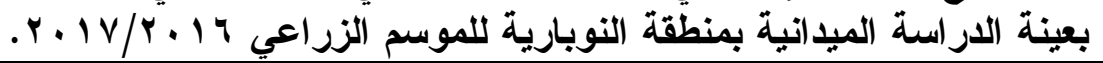

\begin{tabular}{|c|c|c|c|c|c|c|c|}
\hline \multirow[b]{2}{*}{ الترتيب } & \multirow{2}{*}{$\begin{array}{c}\text { المئوزي } \\
\text { الوزن }\end{array}$} & \multirow[b]{2}{*}{ المرجط } & \multicolumn{3}{|c|}{ الاستجابة } & \multirow[b]{2}{*}{ و النسبة } & \multirow[b]{2}{*}{ المشكلات } \\
\hline & & & 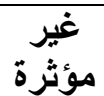 & 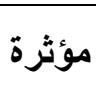 & مؤثرة & & \\
\hline \multirow{2}{*}{ r } & \multirow{2}{*}{$\Lambda \cdot 67$} & \multirow{2}{*}{ r. $\leqslant$ r } & 10 & $\varepsilon$. & 70 & $\varepsilon$ & \multirow{2}{*}{ ارتفاع أسعار الأسمدة والكيماويات } \\
\hline & & & $1 r_{6} 0$ & Tr. & $0 \varepsilon_{6} Y$ & $\%$ & \\
\hline \multirow{2}{*}{1} & \multirow{2}{*}{$\left.17_{6}\right)$} & \multirow{2}{*}{ r.01 } & 1. & $r$. & A. & $\varepsilon$ & \multirow{2}{*}{ والتشغيل للصوب الزراعية الاتشاء والصياتة } \\
\hline & & & $\Lambda_{6}{ }^{r}$ & TO & $77 . V$ & $\%$ & \\
\hline \multirow{2}{*}{$\varepsilon$} & \multirow{2}{*}{77.6} & \multirow{2}{*}{ r } & $\varepsilon$. & $\varepsilon$. & $\varepsilon$. & $\varepsilon$ & \multirow{2}{*}{ ارتفاع أسعار الفائدة على القروض } \\
\hline & & & r.r & Tr. & TrG & $\%$ & \\
\hline \multirow{2}{*}{ r } & \multirow{2}{*}{$V V_{6} \Lambda$} & \multirow{2}{*}{ 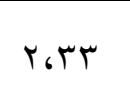 } & $r$. & $\varepsilon$. & 7. & $\varepsilon$ & \multirow{2}{*}{ المقدمة للزراع تكاليف الخذمات التسويقية } \\
\hline & & & 17.8 & 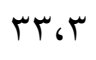 & 0 . & $\%$ & \\
\hline - & $V V_{6} \wedge$ & T.tr & - & - & - & - & المتوسط \\
\hline
\end{tabular}

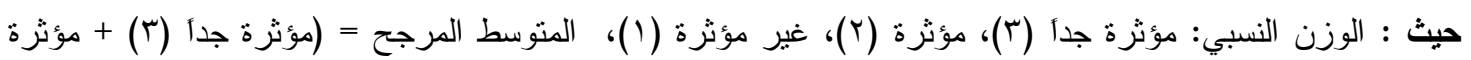

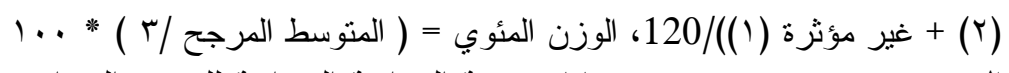

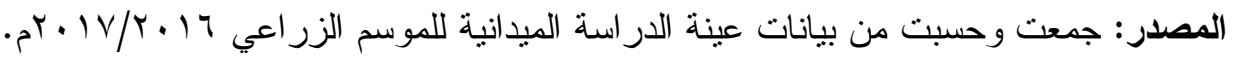

وجاءت مشكلة ارتفاع أسعار الفائدة على القروض في الترتيب الخامس من حيث الأهمية

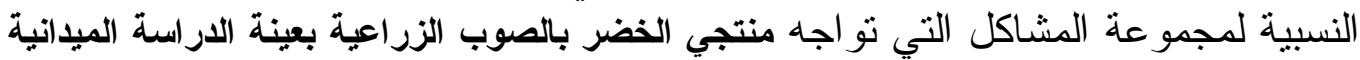

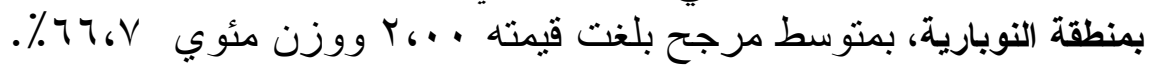
وبإجر اء تحليل التباين فى اتجاه واحد بين المشكلات الفنية لوحظ وجود فئهون فروق ذات ذات دلالة

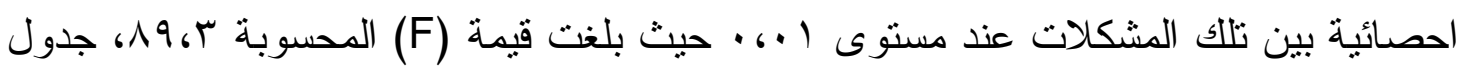

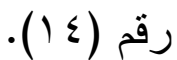

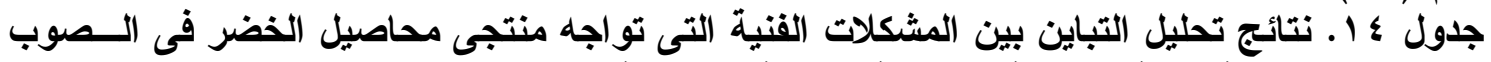

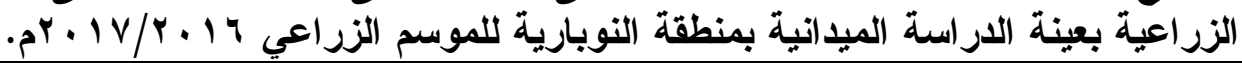

\begin{tabular}{|c|c|c|c|c|}
\hline قالمسية (F) & متوسط مجموع مربعات & مجموع مربعات & درجات الحرية & مصدر الاختلاف \\
\hline$* *(\vee \neg$ \ $\vee)$ & 79 & $T \cdot V$ & r & بين المشكلات \\
\hline - & .6 .9 & $r+96 r$ & YTV & داخل المشكلات \\
\hline - & - & $\varepsilon \leqslant T_{6}, r$ & TV. & المجموع \\
\hline
\end{tabular}

حيث أن (***) تشير إلى معنوية قيمة (F) المحسوبة عند مستوى معنوية ا .،. .. المصدر : جمعت وحسبت من بيانات عينة الدر اسة الميدانية.

\section{وفى ضوء النتائج التى توصل إليها البحث يمكن التوصية بما يلى}

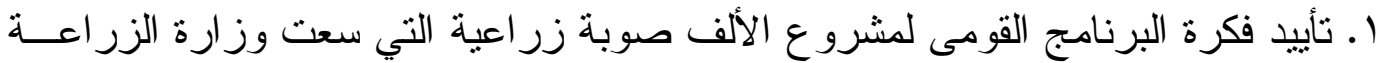

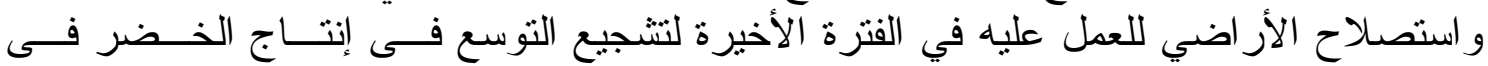


الصوب الزر اعية على مستوى الجمهورية، حيث ثبت نجاحها في زيادة إنتاجية وحسـني الأرض ومياه الري.

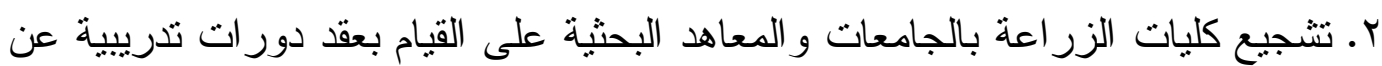

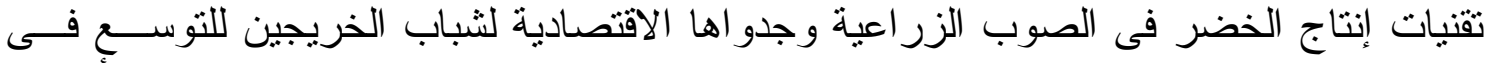

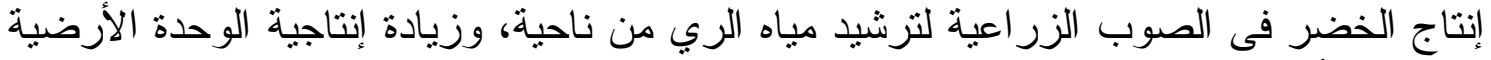

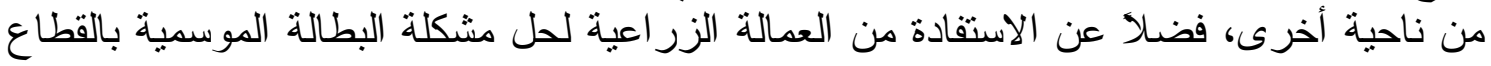
الزر اعي.

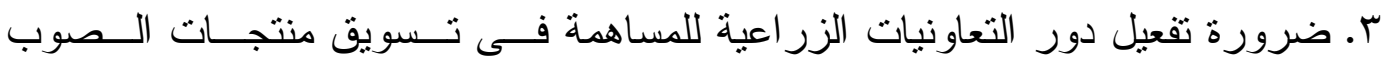

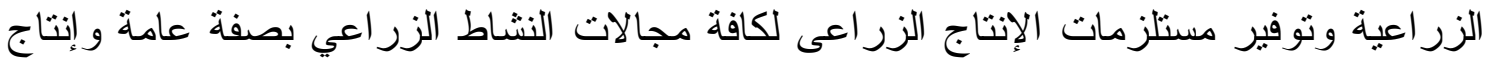

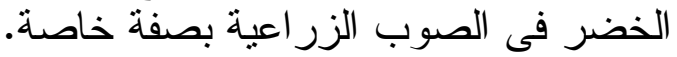

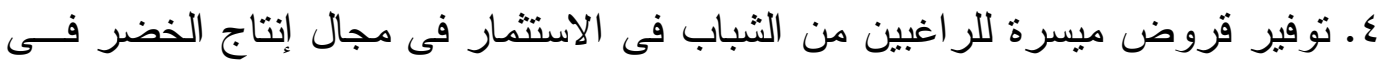

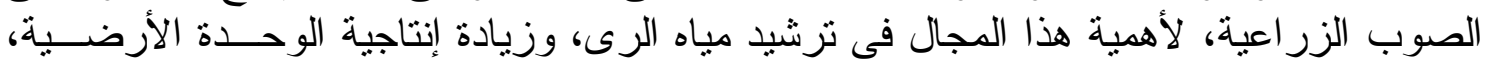
وزيادة كفاءة عنصر العمل ومن ثم مجابهة البطالة الموسمية.

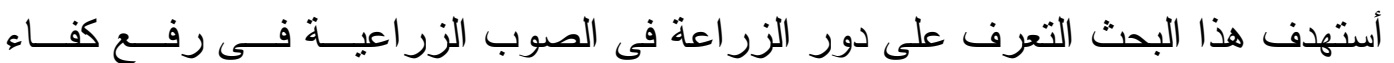

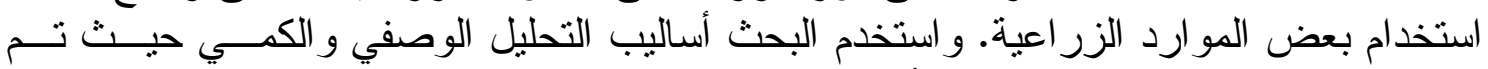

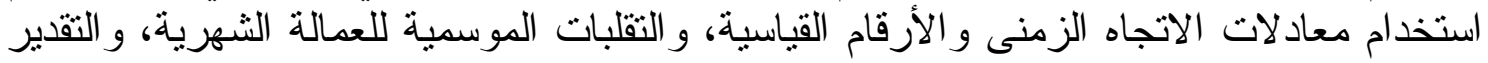

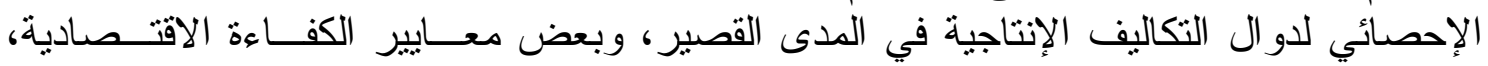

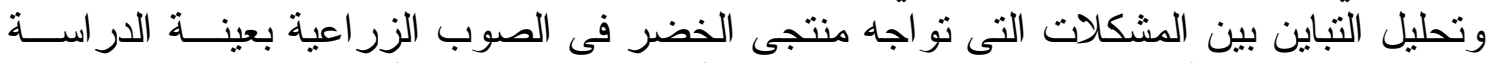
الميدانية، ولتحقيق أهداف البحث فقد اعتمد بصفة أساسية على بيانات أولية لعينة ميدانية حجمها لئها

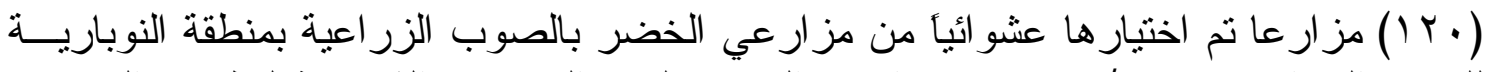

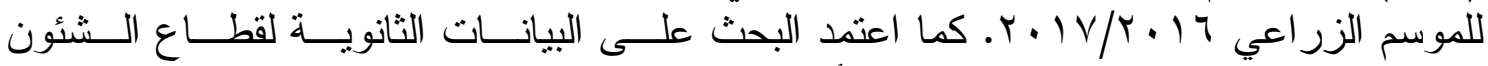

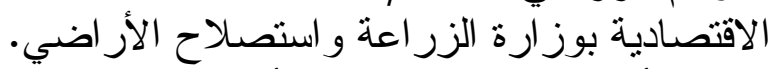

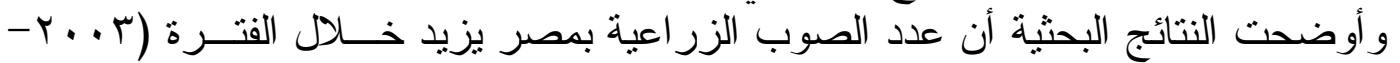

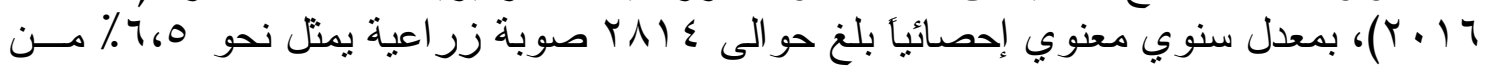

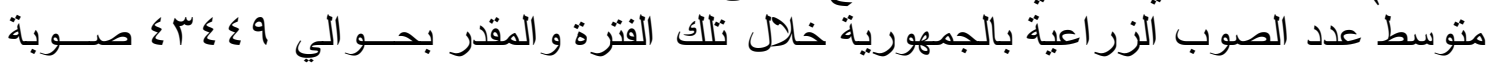

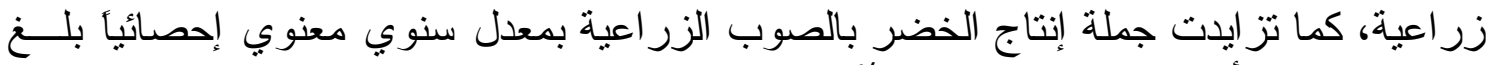

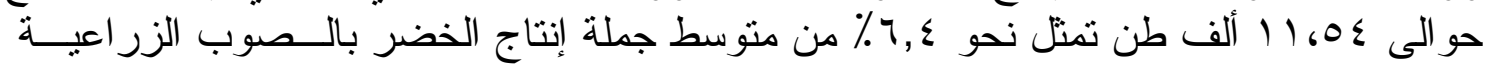

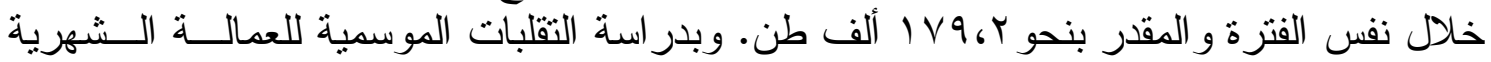

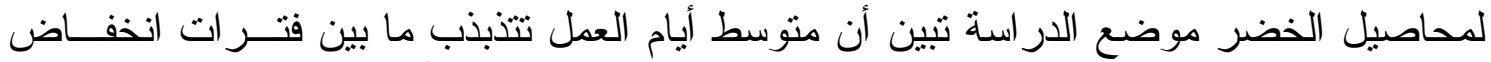

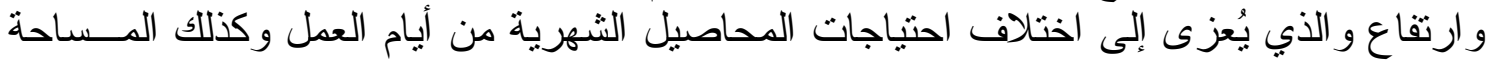

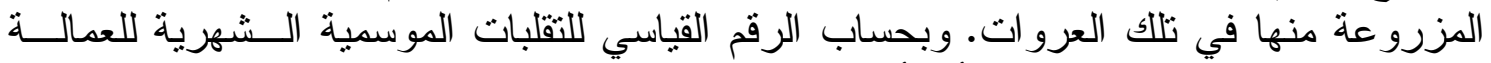

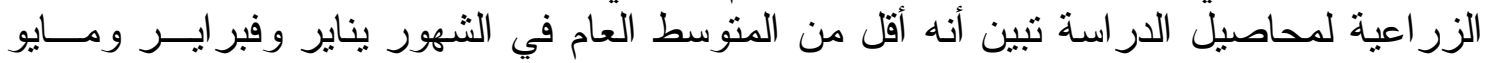

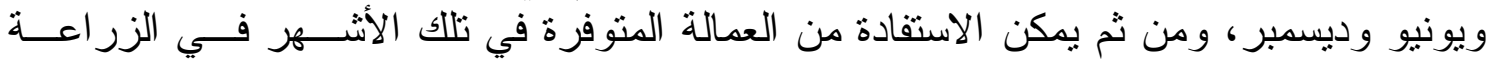
بالصوب الزر اعية.

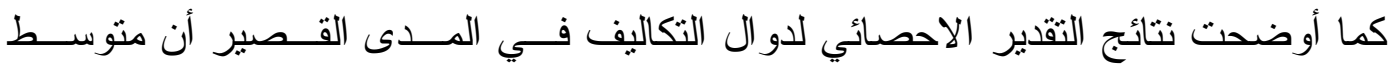

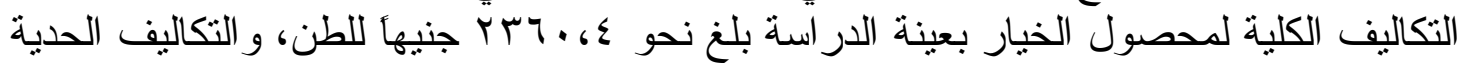

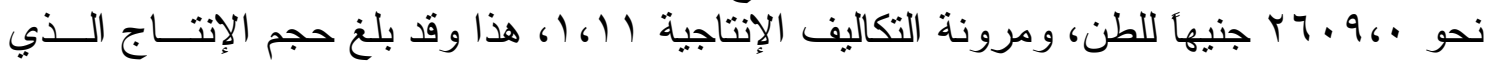

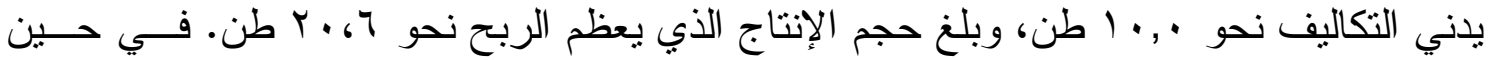

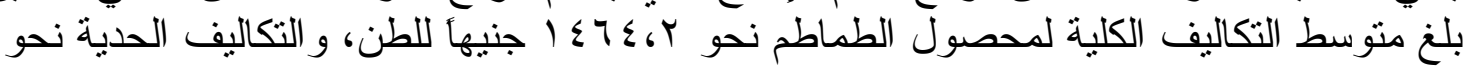




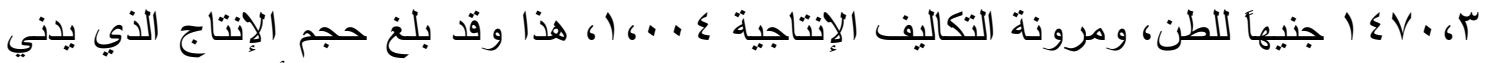

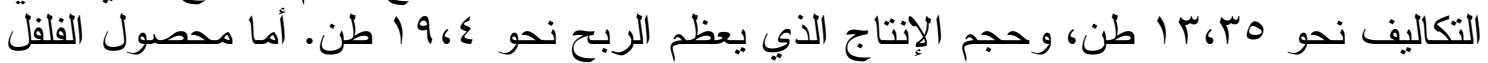
فقد بلغ متوسط التكاليف الكلية له نحو

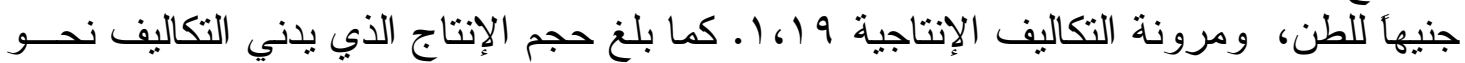

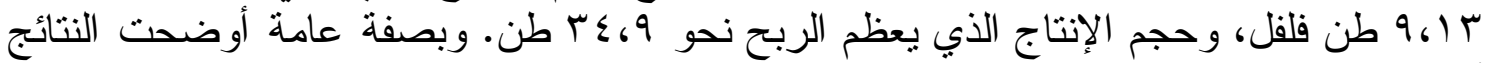

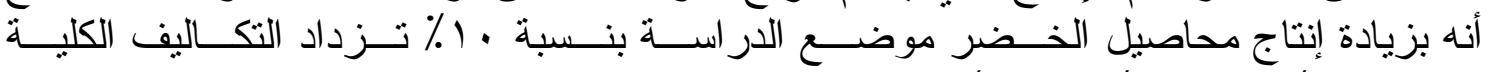

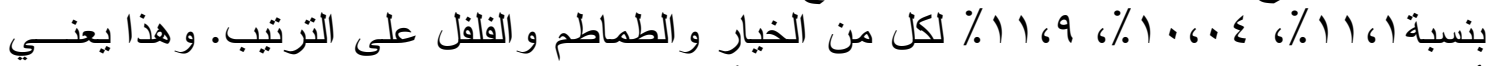

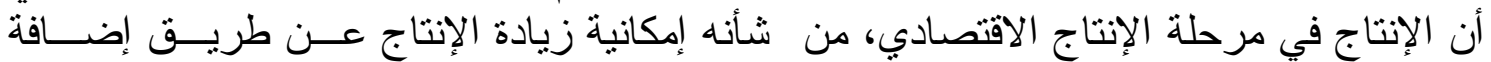

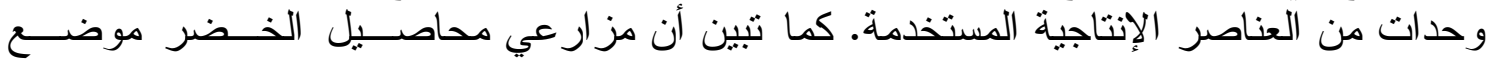

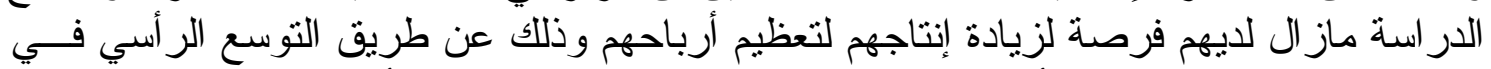

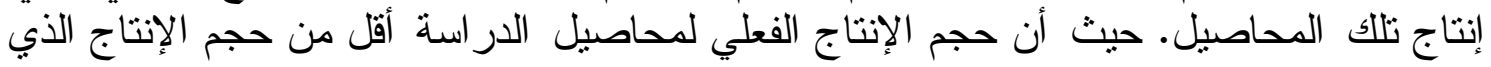
يدني التكاليف و الأي يعظم الربح الربح.

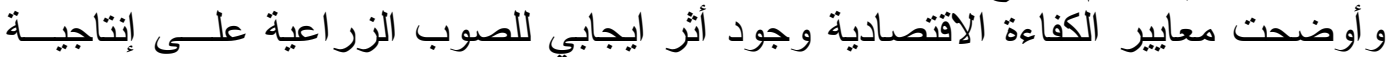

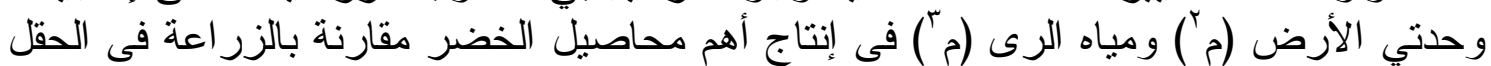

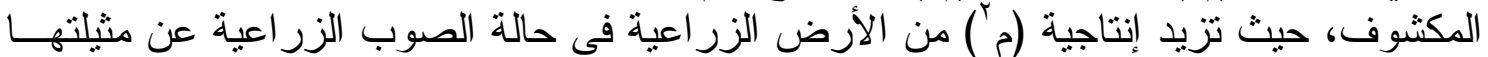

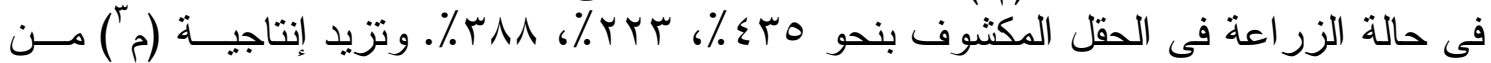

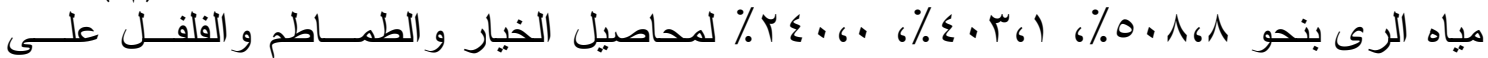
الترثيب.

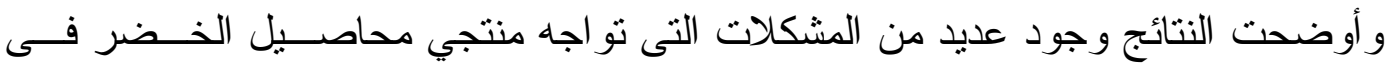

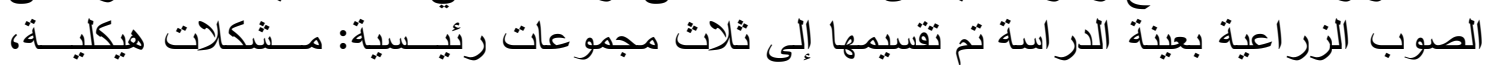

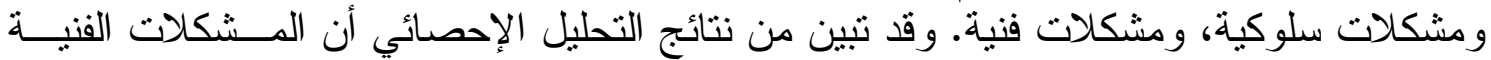

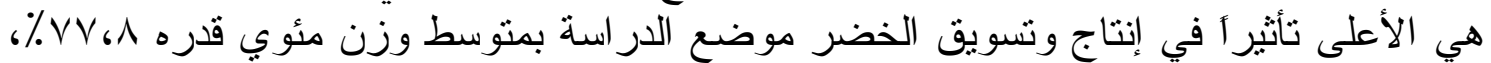

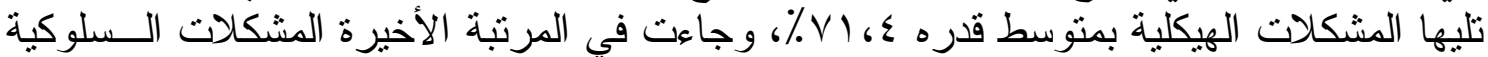
بمتوسط قدره 0 ، $17 \%$

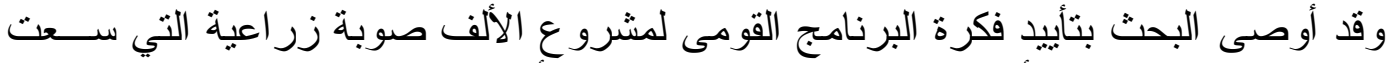

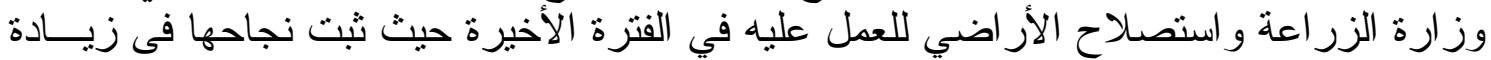

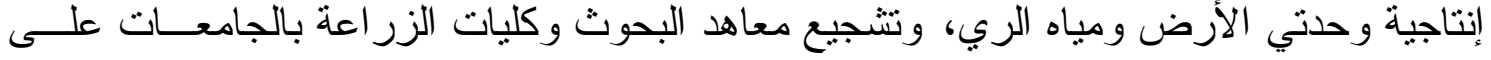

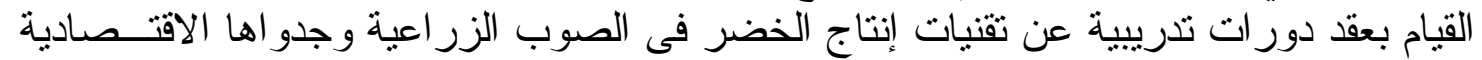

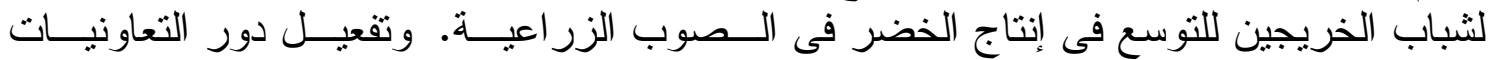

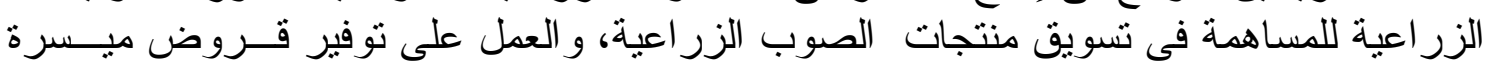

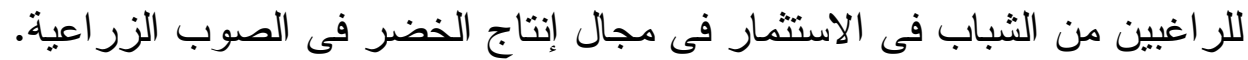

ا ـ أحمد توفيق مصطفى (دكتور)، تقنيات مستدامة لإنتاج محاصيل عالية القيمة مــن الزر اعــة الزية

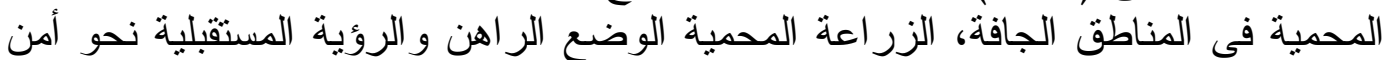

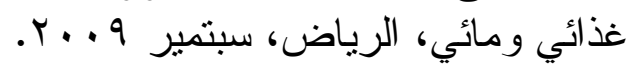

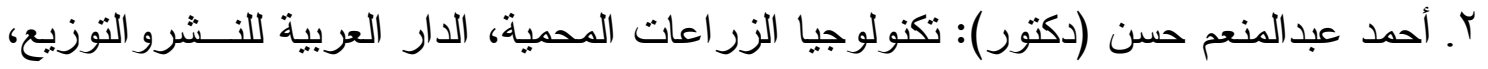

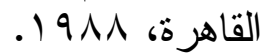

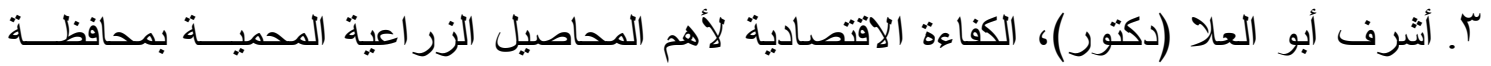

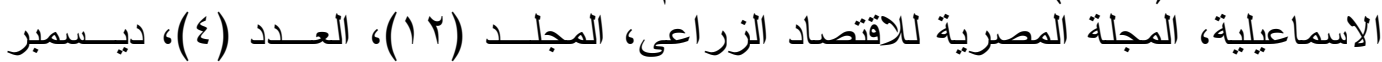




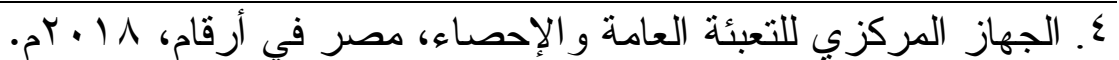

0. حنفي عبد الحق (دكتور)، الممارسات الزر اعية الجيدة (GAP) و المكافحة الحيوية للمحاصيل

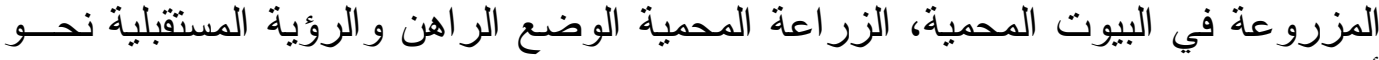

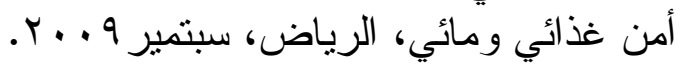

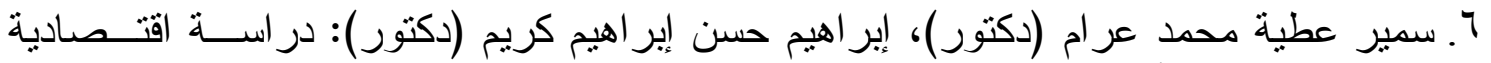

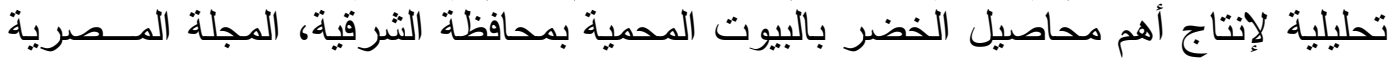

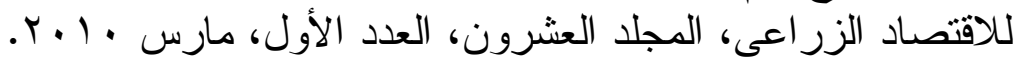

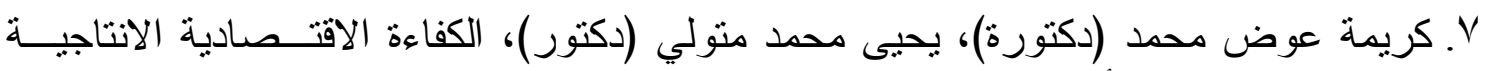

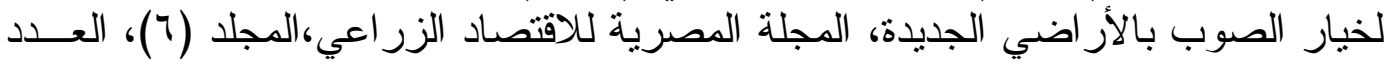

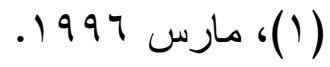

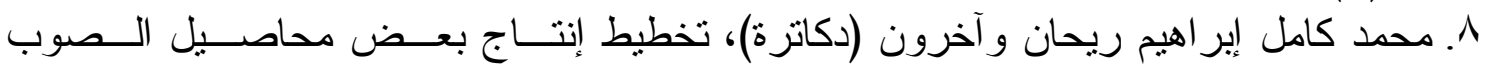

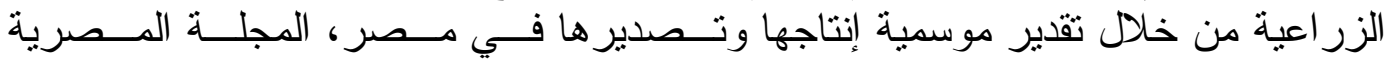

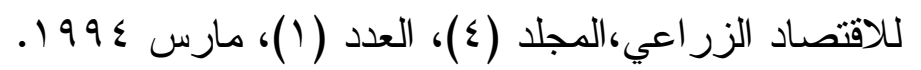

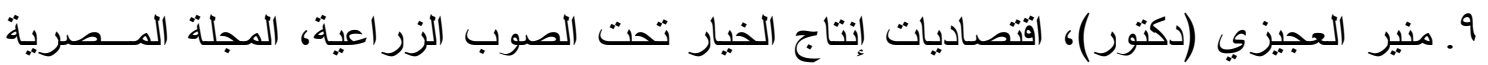

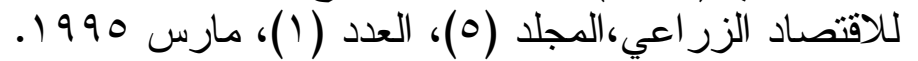

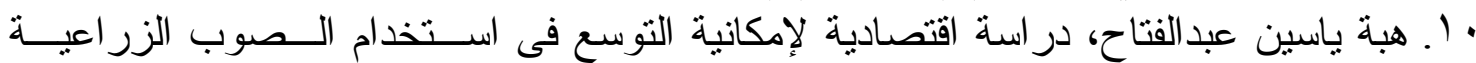

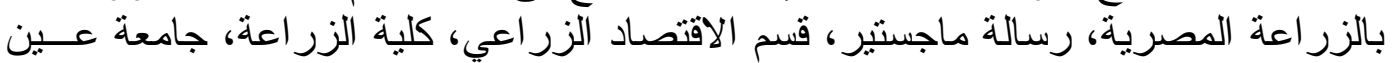

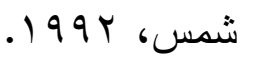

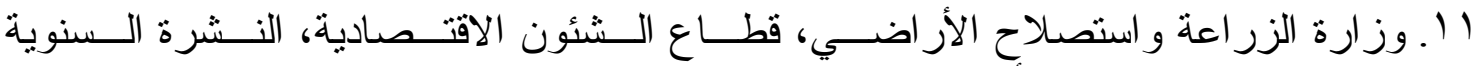

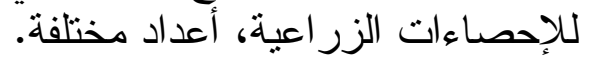

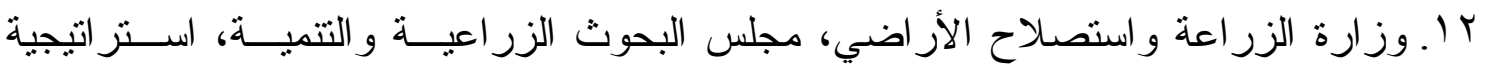

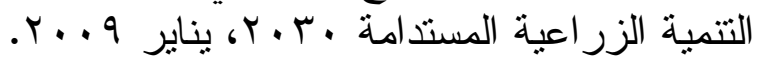

ثانياً: المراجع الأجنبية:

13. Abdel Hamid Youssef Saad. (2001). "Study On New Land Statistics", Economic Affairs Sector, MALR \& Reform, Design And Reimplementation Unit/APRP, Report No.151.

14. Hall, B.F. and Lavern, E.P. (1978). "Farm Size and Economic Efficiency", the case of California Ames, J. of Econ, Vol. 60, N. 4.

15. Heady, E.O. and Dillon, J.L. (1961). "Agricultural Production Functions" Iowa State University Press, Ames, Iowa, U.S.A. 


\title{
An Economic Study of the Impact of the Greenhouses on the Efficiency of Using Some Agricultural Resources in Egypt
}

\author{
Saied, Maha A.Iand Manar E.Bayoumi \\ ${ }^{1}$ Department of Agricultural Economics, Faculty of Agriculture, Ain Shames Univ., \\ Cairo, Egypt. \\ ${ }^{2}$ Agribusiness and Consumer Sciences Dep., Collage of Agricultural and Food \\ Sciences, King Faisal Univ. Kingdom of Saudi Arabia. \\ ${ }^{3}$ Agricultural Economics Institute-Department of Rural Communtiy-Development, \\ Agric.Res.Center, Cairo, Egypt.
}

\section{Summary}

This research aimed to identify the role of agriculture in greenhouses in raising the efficiency of some agricultural resources. The study used descriptive and quantitative analysis methods. The objectives of the research were mainly based on preliminary data for a randomly selected field samples from vegetable producers in the Nubaria region its size (120) farmers, for the agricultural season 2016/2017.

The results showed that the number of greenhouses in Egypt increased during the period (2003-2016) at a statistical annual average of about 2814 greenhouse, representing about $6.5 \%$ of the average number of greenhouses in the Republic during that period. Total vegetable production of greenhouses increased at a statistically significant annual rate of about 11.54 thousand tons. The seasonal fluctuations of the monthly labor of vegetable crops studied, it was found that the average working days fluctuated between periods of decline and height, which is due to the different needs of the monthly crops of working days as well as the area cultivated. The monthly seasonal fluctuations of agricultural labor for the study crops were found to be lower than the general average in January, February, May, June, and December.

The results of the statistical estimation of the cost functions in the short run showed that the average total cost of the cucumber crop in the sample amounted to about 2360.4 LE per ton, the marginal costs of about 2609.0 LE per ton, and the elasticity of the costs of 1.11. Production which maximizes profit is about 20.6 tons. The total cost of the tomato crop was about LE 1464.2 per ton. The marginal costs are about LE 1470.3 per ton. The elasticity of the costs is 1.004 . The production, which maximizes profit, is about 19.4 tons. The pepper crop has a total average cost of about 2441.5 LE per ton, marginal costs of about 2915.3 LE per ton, and elasticity of costs 1.19 . The production, which maximizes profit, is about 34.9 tons of pepper. In general, the results showed that by increasing the production of vegetable crops by $10 \%$, the total costs increased by $11.1 \%$, $10.04 \%$ and $11.9 \%$ for cucumbers, tomatoes and pepper, respectively. This means that production is at an economic production stage, which means that it is possible to increase production by adding units of the productive elements used. It has also been shown that farmers in the vegetable crops under study still have the opportunity to increase their production to maximize their profits by vertical expansion in the production of those crops. 

http://ajas.journals.ekb.eg/

The economic efficiency criteria showed a positive effect on the productivity of land $\left(\mathrm{m}^{2}\right)$ and irrigation water $\left(\mathrm{m}^{3}\right)$ units in the greenhouses compared to agriculture in the open field, where the productivity of $\left(\mathrm{m}^{2}\right)$ of land in greenhouses increase than in the case of agriculture in the open field by $435 \%$, $223 \%$ and $388 \%$, and the productivity of $\left(\mathrm{m}^{3}\right)$ of irrigation water increase by $508.8 \%, 403.1 \%$ and $240.0 \%$ for cucumbers, tomatoes and peppers, respectively.

The results indicated that there are many problems facing the producers of greenhouses, which were divided into three main groups: structural problems, behavioral problems and technical problems. The results of the statistical analysis showed that the technical problems were the most influential with an average weight of $77.8 \%$, followed by structural problems with an average of about $71.4 \%$, and last ranked behavioral problems with an average of $61.5 \%$.

The research recommended supporting the idea of the national program of the "Thousand Greenhouses" project, and encouraging research institutes and colleges of agriculture in universities to hold training courses on greenhouses and the economic feasibility of young graduates to expand the production of greenhouses. Activate the role of agricultural cooperatives to contribute to the marketing of agricultural products, and work to provide soft loans for young people interested in investment in the greenhouses. 